\title{
Developing a Hypothetical Multi-Dimensional Learning Progression for the Nature of Matter
}

\author{
Shawn Y. Stevens, César Delgado, Joseph S. Krajcik \\ School of Education, University of Michigan, 610 East University Avenue, \\ Ann Arbor, Michigan 48109-1259
}

Received 10 July 2008; Accepted 12 June 2009

\begin{abstract}
We describe efforts toward the development of a hypothetical learning progression (HLP) for the growth of grade 7-14 students' models of the structure, behavior and properties of matter, as it relates to nanoscale science and engineering (NSE). This multi-dimensional HLP, based on empirical research and standards documents, describes how students need to incorporate and connect ideas within and across their models of atomic structure, the electrical forces that govern interactions at the nano-, molecular, and atomic scales, and information in the Periodic Table to explain a broad range of phenomena. We developed a progression from empirical data that characterizes how students currently develop their knowledge as part of the development and refinement of the HLP. We find that most students are currently at low levels in the progression, and do not perceive the connections across strands in the progression that are important for conceptual understanding. We suggest potential instructional strategies that may help students build organized and integrated knowledge structures to consolidate their understanding, ready them for new ideas in science, and help them construct understanding of emerging disciplines such as NSE, as well as traditional science disciplines. (C) 2009 Wiley Periodicals, Inc. J Res Sci Teach 47: 687-715, 2010
\end{abstract}

Keywords: learning progression; secondary; qualitative; integrated knowledge; undergraduate

Recent scientific research has revealed that matter exhibits novel, often unexpected properties as it transitions between the bulk form and that of individual atoms and molecules. This transition generally occurs at the nanoscale, where at least one dimension measures between $10^{-9}$ and $10^{-7} \mathrm{~m}$. Scientists and policy-makers predict that the new information and technologies resulting from nanoscale science and engineering (NSE) research will have extensive societal implications that may be realized in a broad range of areas, including health care, agriculture, food, water purification, and energy and environmental concerns (PCAST, 2005). These predictions have created a need to incorporate ideas related to NSE into the science curriculum.

A foundation for NSE literacy must include a robust model of the nature of matter, which includes the structure of matter, how it behaves and interacts, as well as its properties and what determines those properties. These ideas are also the foundation of understanding chemistry and are considered important aspects of science literacy (American Association for the Advancement of Science [AAAS], 1993; National Research Council [NRC], 1996). Due to the extensive nature of the science content, we will focus on only a portion of it in this manuscript. We describe our efforts toward the development of a hypothetical learning progression (HLP) that characterizes a path along which grade 7-14 students may develop more sophisticated models of atomic structure, and the electrical forces that govern interactions at the nano-, molecular, and atomic scales. Each of these knowledge domains represents a significant portion of one or more big ideas of NSE (Stevens, Sutherland, \& Krajcik, in press). We followed an iterative, design-based research process to ensure the science content, the instructional strategies to help students to develop understanding of the content, and assessments to place students along the HLP were aligned.

\footnotetext{
Contract grant sponsor: National Science Foundation; Contract grant numbers: 0426328 and 0822038.

Correspondence to: S.Y. Stevens; E-mail: sstevens@umich.edu

DOI 10.1002/tea.20324

Published online 5 August 2009 in Wiley InterScience (www.interscience.wiley.com).
} 
The atomic and kinetic theories provide a basis for understanding the structure and behavior of matter, providing a means for explaining a vast number of phenomena. Although a basic particle model allows students begin to develop explanations of many phenomena (e.g., phase changes, smells traveling across a room), a more scientifically accurate model of atomic structure and knowledge about the way atoms and molecules interact expands the range of phenomena and increases the level, in this case scientific accuracy, of the explanations (e.g., chemical reactions, dissolving, balloons "sticking" to the wall). Despite the emphasis that is already placed on these content domains in the science curriculum, students continue to have difficulty developing conceptual understanding of this science content (Harrison \& Treagust, 1996; Levy Nahum, Mamlock-Naaman, Hofstein, \& Krajcik, 2007; Taber \& Coll, 2002).

\section{Theoretical Framework}

\section{Learning Progressions}

In order for students to develop conceptual understanding of complex ideas such as the model of atomic structure and how atoms and molecules interact, they must experience a curriculum that coherently supports their learning over several years. Unfortunately, curriculum materials based upon national, state or local science education standards tend to support shallow coverage of a broad range of concepts instead of the development of an integrated understanding of a few key ideas (Schmidt, Wang, \& McKnight, 2005). Learning progressions (LPs) provide a promising means of organizing and aligning the science content, instruction and assessment strategies to provide students with the opportunity to develop deep and integrated understanding of a relatively small set of big ideas of science over an extended period of time. However, the science education community has yet to reach a consensus on the definition of LPs or the methodology for developing them. For instance, researchers disagree on span and grain size of LPs. Here we discuss our working definition of an LP.

An LP describes how students can potentially move toward more sophisticated understanding of a big idea of science over a broad, defined period of time (Duschl, Schweingruber, \& Shouse, 2007; Smith, Wiser, Anderson, \& Krajcik, 2006). The move towards greater expertise may be sequential in nature such that understanding of topic $\mathrm{A}$ is required before students can develop understanding of topic B. Alternatively, an LP may describe how students develop a more complex model, where knowledge of topic A becomes more sophisticated by incorporating more ideas and connecting to ideas of other related topics (i.e., developing a more scientifically accurate model; Stevens, Shin, Delgado, Krajcik, \& Pellegrino, 2007).

The range of content addressed by an LP is defined by lower and upper anchors (Duschl et al., 2007; Mohan, Chen, \& Anderson, in press). A description of the knowledge held and needed by students prior to developing understanding of concepts contained in the LP provides a lower anchor, or starting point. The knowledge and skills students are ultimately expected to have at the end of the progression, the upper anchor, or endpoint, is drawn from societal expectations and goals of science literacy as well as education research about learning in the discipline (Duschl et al., 2007; Mohan et al., in press). LPs describe qualitatively different levels of understanding that students' progress through as they move towards the upper anchor. Each level of the progression describes comprehensible and developmentally appropriate steps toward more sophisticated understanding of the big idea. Empirical learning research should guide the description of the levels, as well as when and how it might be appropriate to introduce the concepts to students. However, previously reported learning difficulties may be overcome if better instructional strategies are employed to support student learning (Margel, Eylon, \& Scherz, 2008); thus, developing LP is an iterative process. Because learning is a nonlinear process (Caravita \& Halldén, 1994), the levels of an LP do not necessarily describe a unidirectional route to more sophisticated understanding. For example, in certain cases it may be a useful to step back to a simpler model to help students develop understanding of more complex ideas. However, the ideas included in the LP must be productive in that they describe knowledge that helps students develop more sophisticated understanding.

LPs are not developmentally inevitable, as many factors determine the path that students may follow as they build understanding of a big idea, including the context, curriculum materials, instruction, and students' prior knowledge and experiences. Therefore, any LP must necessarily be considered hypothetical even if it is 
empirically validated for thousands of students; an LP or learning trajectory can never be described as the only, or the best way to move all students along towards understanding (Baroody, Cibulskis, Lai, \& Li, 2004).

\section{Developing Conceptual Understanding}

Conceptual understanding implies that students have the ability to use knowledge, apply it to related problems, and to make connections between related ideas (Bransford, Brown, \& Cocking, 2000). Ideally, the sense-making involved in building conceptual understanding involves taking newly introduced information and connecting it to existing knowledge as the student builds an organized and integrated structure (Ausubel, 1968; Linn, Eylon, \& Davis, 2004; Taber, 2001a). However, students often enter class with inaccurate and incomplete knowledge structures into which they are expected to incorporate and organize their new information. Students' knowledge structures may not be organized frameworks but pieces that are not put together in a systematic manner (diSessa, 1988). When ideas are not structured in an organized way, it is difficult for students to apply their knowledge to new situations because it lacks structure and organization; in other words, it is compartmentalized (Sirhan, 2007; Taber, 2004). Therefore, although students may possess relevant pieces of knowledge, they may not be able to access and use their knowledge when facing new problems or ideas. Experts, on the other hand, have well organized and contextualized knowledge that is easy to access, often organized along fundamental principles of the field (Bransford, Brown, \& Cocking, 2000; Chi, Feltovich, \& Glaser, 1981).

Such knowledge structures can only be developed when students are able to (and asked to) use aspects of the knowledge framework in various combinations. However, assessments commonly focus on targeted, isolated topics that do not require students to connect currently taught concepts with concepts from the same area or from other science areas that were previously learned (Pellegrino, Chudowsky, \& Glaser, 2001). As a result, the traditional curriculum and instruction often focuses on isolated bodies of knowledge. Thus, current assessment and instruction practices can largely be described as linear and compartmentalized in nature.

Because experts' knowledge structures are well connected, it is useful to consider the development of conceptual understanding multi-dimensionally, and visualize LPs as strategic sequencing that promotes both branching out and forming connections between ideas related to a core scientific concept. In this case, an LP would describe a progression of sets of ideas instead of isolated strands of knowledge (Stevens, Shin, Delgado, \& Krajcik, 2007). Thus an LP should identify and characterize not only the ways in which students develop understanding of the important concepts within individual knowledge domains, but also the connections among related concepts both within and across domains (see Figure 1). In order to explain scientific phenomena, students must commonly incorporate ideas from multiple topics. For example, to explain chemical changes, students must connect a range of ideas including the relationship between atoms and molecules, the electrical forces that govern their interactions, the structure and motion of atoms and

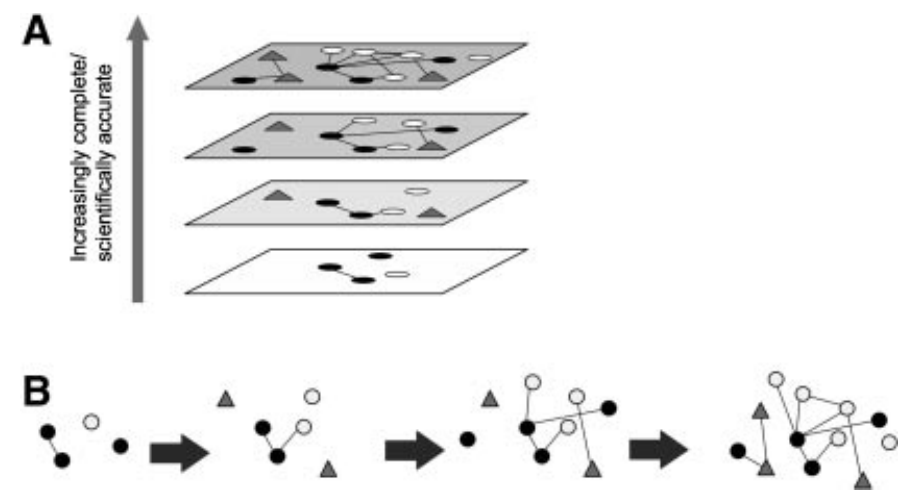

Figure 1. Representations of the development of integrated knowledge, or conceptual understanding. Each color (or shape) represents a different construct. The black lines represent the ideal connections between the ideas within and across different constructs. (A) Represents multi-dimensional development of knowledge and (B) is a 2D representation of the process of integration and organization of knowledge structures. 
molecules and the effect of their environment on their behavior, energy elements and periodic trends. As students develop more sophisticated understanding, new ideas may be added to and integrated with previous knowledge while others remain isolated until new ideas introduced later help students organize it. At times, new ideas cause a reorganization of the older ideas in order to accommodate new experiences (Piaget, 1983).

\section{Defining the Upper and Lower Anchors of the Learning Progression}

\section{Lower Anchor}

Smith et al. (2006) developed an LP that describes how grade K-8 students can develop a more sophisticated understanding of the atomic molecular theory. The HLP we are developing to describe how students can develop a more sophisticated understanding about the structure, properties, and behavior of matter builds on this progression. The scope of the content becomes significantly broader as the model becomes more sophisticated. Therefore, here we are limiting our focus to how students' understanding of the models of atomic structure and the electrical forces that govern interactions at small scales develops from grades 7 to 14 .

Using the K-8 HLP for the atomic molecular theory and additional empirical research as a guide (Smith et al., 2006), we defined the lower anchor for our HLPs. By the late elementary grades, students should define matter as anything that takes up space and has weight. They should know that matter can exist in several forms - solid, liquid, or gas - and that within a sealed system, the amount of matter stays the same even if it changes form (AAAS, 1993; NRC, 1996). The ideas that the same substance can exist in multiple forms and that the amount is conserved through transformations between states are often introduced with the water cycle during the mid- to late elementary grades (Lee \& Tan, 2004). At this age, students should understand that matter is made up of particles that are too small to see with the unaided eye. They do not need to refer to these particles as atoms or molecules at this time. In fact, students at this level tend to use the terms atom, molecule, and particle interchangeably (Harrison \& Treagust, 2002).

Late elementary students should have an understanding that a force acts to push or pull on an object and that it is possible to exert a force on another object without touching it (AAAS, 1993). Students commonly have some experience with magnets and electricity in elementary school. However, their experience may be limited to magnetic forces. Likewise, they may be familiar with the rule that "opposites attract and likes repel," but may only connect it to magnetic poles and not electrical charges.

\section{Upper Anchor}

The upper anchor of the HLP was defined based upon national standards documents (AAAS, 1993; NRC, 1996), ideas required as a foundation for NSE learning (Stevens et al., in press) and current learning research related to those expected understandings.

Models for atomic structure of varying complexity are useful for explaining different phenomena. Although the Schrödinger model of the atom has the most explanatory power, a true quantum-mechanical model of the atom is beyond the upper anchor of this progression. Benchmarks (AAAS, 1993) describes how the electron configuration, particularly the outermost electrons determine how atoms interact with each other. This implies a model of atomic structure that includes electrons distributed in shells. High school chemistry courses often include complex ideas such as bond polarity, polarizability, and induced dipole interactions (Atkins \& Jones, 1997; Stanitski, Eubanks, Middlecamp, \& Stratton, 2000), which require a basic electron cloud model that includes a probabilistic distribution of electron density and allows for shifts in electron density. While the quantization of energy is represented in the national standards (AAAS, 1993; NRC, 1996), there is no discussion of uncertainty in terms of atomic systems. There is evidence that high school and lower undergraduate students can develop a basic quantum mechanical model of atomic structure that includes a probabilistic model of electron behavior (Petri \& Niederer, 1998). While some connection to the waveparticle duality for electrons and thinking about electron distribution in terms of probability should be incorporated into the model, concepts such as wave functions are not appropriate at this level (Stevens et al., in press). In order to meet the expected need for a nano-literate workforce, quantum mechanical ideas become more important, so we must develop and test some pedagogic strategies to successfully help students to develop a qualitative conceptual understanding of this content. 
When they reach the upper anchor, students should be able to describe interactions between atoms, molecules and nanoscale entities in terms of the electrical forces that govern them. They should also be aware that the outermost, or valence, electrons play an important role in interactions between atoms and molecules (AAAS, 1993) Students should be able to describe the type and relative strength of the interactions (Levy Nahum et al., 2007) for a range of substances. Although the octet model is useful for describing certain interactions, students should consider ideas such as electronegativity and polarizability in their explanations of interactions that occur at very small scales in order to extend the model beyond explanation of only certain types of chemical bonding.

To help all learners arrive at this upper anchor, our nation needs a model of how students develop such understanding. Such a model of learning has been missing from the U.S. curriculum. Our goal is to develop an HLP that describes how students' models for atomic structure and electrical forces that govern interactions at the nano-, molecular, and atomic scales can develop over time. In particular, we focus on the manner in which students incorporate and connect related ideas within the HLP in order to construct an LP that characterizes how students tend to organize and integrate their knowledge. Such models will help learners explain a host of macroscopic, microscopic, and nanoscale phenomena. In addition, we also identify potential instructional strategies to help students move along the HLP.

\section{Methods}

As part of the process of developing and refining an HLP, we also built an empirical progression (EP) that describes how students' understanding develops under the current science curriculum. The EP informs the development and refinement of an HLP in many ways. Despite the progress made in the field, there are still numerous holes in the research literature related to student learning and understanding of important science concepts. In addition, the research studies have been performed in a diverse set of contexts and cultures using a wide range of instructional materials and strategies. Using the same assessments to measure the understanding of students at different levels within the same science curriculum provides an image of how students may develop understanding as a result of current science instruction and whether and how they establish connections across topics. By assessing multiple sets of students, we obtain a broader picture of student learning. Even with the limitations of cross-sectional data, this approach provides a more coherent picture of student learning than comparing disparate research studies. In addition, most educational research focuses on student learning in a single science topic. In our HLP, we also wanted to represent the connections students should make between topics. For instance, what type of atomic model do they employ when discussing chemical bonding, or how do they discuss intermolecular forces in their models of the structure of solids and liquids in comparison to explaining the phenomenon of powdered sugar sticking to a surface more than granulated sugar does. The same student needs to be assessed on each of these topics in order to see if they make connections among them.

Characterizing the current state of student learning allows us to evaluate whether students are progressing toward the upper anchor as conjectured, or if new instructional strategies must be employed to follow the HLP. In particular, an EP provides insight into the concepts with which students struggle, what connections they find easy to make and which are most difficult, and may also help identify threshold concepts, which provide a door to developing understanding of a broad range of phenomena. As the HLP is iteratively refined and empirically tested, the HLP and EP should ultimately merge to form an empirically tested HLP.

\section{Building a Hypothetical Learning Progression}

Consistent with design-based research (Collins, Joseph, \& Bielaczyc, 2004), the development of an HLP is an iterative process. We followed the construct-centered design (CCD) process (Krajcik, Shin, Stevens \& Short, 2009; Pellegrino, Krajcik, Stevens, et al., 2008), which combines aspects of the learning-goal-driven design process for the development of coherent instructional materials (Krajcik, McNeill, \& Reiser, 2008), evidence-centered assessment design (Mislevy \& Riconscente, 2005) and the assessment triangle framework (Pellegrino et al., 2001). Using a systematic process to develop the HLP ensures that the science content of the big idea, instructional strategies and assessments associated with the HLP are aligned. 
The first step of the CCD process is defining the construct(s). A construct includes the ideas or concepts that we wish to learn about and measure. It is assumed that the ideas within a construct are related by a single underlying characteristic (Wilson, 2005). Here, our two constructs are the atomic model (structure) and electrical forces with a focus on covalent and ionic bonding. Using the defined upper and lower anchors as a guide, the principles and theories within the two constructs were unpacked to define what it means to understand them at levels appropriate for grade 7-14 students. By unpacking, we mean breaking up the construct into smaller ideas in order to explicitly specify the content. In particular, concepts that are crucial for developing an understanding of the construct are identified. As a step towards defining how students should know the content, the prior knowledge that is required both within and from other constructs is also specified (see Tables 1 and 2).

The individual ideas that define the construct are then connected with contemporary cognitive and learning research, which help specify potential difficulties students might have learning the content, provide insight into instructional strategies that support student learning, and the prior knowledge that students may typically be expected to have. In addition, phenomena that are relevant to illustrating the concepts are identified and described.

The next step of the CCD process incorporates aspects of evidence-centered design (Mislevy \& Riconscente, 2005; Mislevy, Steinberg, Almond, Haertel, \& Penuel, 2003), which centers around three facets: (a) a claim that describes the knowledge, skills, or other attributes to be assessed or learned; (b) the evidence that describes what behaviors or performances are needed to support the claim; and (c) tasks or situations that will elicit those behaviors or help students develop the knowledge to provide the desired evidence. A set of claims and the evidence and tasks (both learning and assessment) that support them was developed for the relevant content for each of the constructs. The claims describe what we would like students to be able to do with the knowledge and the evidence describes the ideas and the connections within and across constructs we expect in students' explanations and predictions of a range of phenomena. The levels of the HLP were defined based upon the evidence that students would provide at different points of the science curriculum in response to a particular task as supported by the research literature. The development of the

Table 1

Science content defined between the upper and lower anchors for the hypothetical learning progression for atomic structure

\section{Atomic Structure}

Atoms are made up of electrons, neutrons, and protons

Protons are positively charged, electrons negatively charged and neutrons are neutral

Protons and neutrons are of similar mass, but electrons have a much smaller mass

The number of protons defines the type of element and is the atomic number on the Periodic Table

Neutral atoms of the same type (element) have the same number of protons and electrons, but not necessarily the same number of neutrons

Different numbers of neutrons for a given number of protons creates different isotopes of the same element

The nucleus takes up only a very small percentage of the volume of an atom, but makes up the vast majority of the atomic mass

The electrons are distributed in "shells" that surround the nucleus. These shells represent energy levels $(n)$

The outer shell of electrons is different than the inner shells of electrons. The inner shells plus the nucleus make up the atomic core

The configuration of the outermost electrons determines how an atom can interact with other atoms

Each shell (or level) of an atom contains a certain number of orbitals (e.g., $1-1 s ; 2-2 s, 2 p_{x}, 2 p_{y}, 2 p_{z}$ )

Two electrons are allowed in each orbital ( $\operatorname{spin}=+\frac{1}{2}$ or $-\frac{1}{2}$ ). This is predicted by the Pauli Principle (i.e., no two electrons can have the same quantum state within an atom)

Electron distribution within an atom cannot be predicted well by the solar system model; electrons are better described by the electron cloud model, which describes the electron probability density

Electrons exhibit particulate and wavelike behavior

The position and momentum of an electron cannot be determined simultaneously (Heisenberg's Uncertainty Principle)

Energy changes in isolated atoms (or molecules and other confined systems) can only occur in certain defined (quantized) amounts

Different energy levels are associated with different configurations of atoms (and molecules) 
Table 2

Science content defined between the upper and lower anchors for the hypothetical learning progression for electrical forces

Electrical Forces

Electrical forces depend on charge. There are two types of charge-positive and negative. Opposite charges attract; like charges repel

The outer shell of electrons is important in inter-atomic interactions. The electron configuration in the outermost shell/ orbital can be predicted from the Periodic Table

Properties such as polarizability, electron affinity, and electronegativity affect how a certain type of atom or molecule will interact with another atom or molecule. These properties can be predicted from the Periodic Table

Electrical forces generally dominate interactions on the nano-, molecular, and atomic scales

Attractions and repulsions between atoms and molecules affect the structure and behavior of matter

An ion is created when an atom (or group of atoms) has a net surplus or deficit of electrons

Certain atoms (or groups of atoms) have a greater tendency to be ionized than others

A continuum of electrical forces governs the interactions between atoms, molecules and nanoscale objects

The attractions and repulsions between atoms and molecules can be due to charges of integer value, or partial charges. The partial charges may be due to permanent or momentary dipoles

When a molecule has a permanent electric dipole moment, it is a polar molecule

Instantaneous induced dipole moments occur when the focus of the distribution shifts momentarily, thus creating a partial charge. Induced dipole-induced dipole interactions, result from the attraction between the instantaneous electric dipole moments of neighboring atoms or molecules

Induced dipole-induced dipole interactions occur between all types of atoms and molecules, but increase in strength with an increasing number of electrons

Polarizability is a measure of the potential distortion of the electron distribution. Polarizable atoms and ions exhibit a propensity toward undergoing distortions in their electron distribution

The environment (e.g., relative concentration of the interacting entities, polarity of solvent, $\mathrm{pH}$, temperature, pressure) plays an important role in our ability to predict and explain the interaction between two entities

claims and evidence were informed by the national standards documents (AAAS, 1993; NRC, 1996) and the learning research literature. See Table 3 for an example of this process.

Developing an Empirical Progression (EP)

Instrument. We used the CCD approach to design open-ended assessment tasks that measured students' understanding of the structure of matter; its properties and the source of those properties; the atomic model; and the forces and interactions that occur between atoms and molecules. The questions were incorporated into a 20- to 30-minute semi-structured interview performed with individual students to characterize their understanding of these topics. The interview included both situations similar to those students might see in the classroom as well as questions requiring them to apply their knowledge to explain real world phenomena.

In the portion of the interview relevant to the ideas discussed in this manuscript, we first asked students about what atoms are and why they are important, then asked them to draw their model of an atom and explain it. If their models included electrons, protons, and neutrons, we asked them to compare the properties of the sub-atomic particles. In addition, we asked whether the relative numbers of the sub-atomic particles is important and why. Based upon their models, students were questioned about their ideas regarding electron distribution and motion. Finally, students were asked why sodium and chlorine interact to form $\mathrm{Cl}_{2}$ and $\mathrm{NaCl}$ and to describe the interactions that occur between the atoms in these substances. See Appendix A for full interview protocol. Although a certain range of answers could be predicted, the conditional nature of the interview typically required extensive unscripted questioning in order to clarify and confirm students' understanding. Despite efforts to minimize interviewer variability (e.g., discussion of protocol, rounds of practice and observation), the conditional nature of the interview and multiple interviewers resulted in slightly different sets of questions for each student. The interviews were conducted in several phases. After each phase, we evaluated student responses and revised the protocol to better characterize student understanding of the constructs.

Participants. The students in this study belonged to three distinct populations. Middle and high school students from two different school systems were interviewed. One set of students attended a public school 
Table 3

An example of the claims, evidence, and tasks for assessing student understanding of ideas related to the nature of matter

\begin{tabular}{|c|c|c|}
\hline Claim & Evidence & Task \\
\hline Students Should be Able to: & The Student Work Should Include: & Students Respond to: \\
\hline $\begin{array}{l}\text { relate the structure and } \\
\text { composition of an atom } \\
\text { to the properties and } \\
\text { behavior of atoms of } \\
\text { various elements }\end{array}$ & $\begin{array}{l}\text { an explanation that includes: } \\
\text { atoms are made of electrons, neutrons and } \\
\text { protons } \\
\text { the number of protons determines the type } \\
\text { of element } \\
\text { the outermost electrons determine how an } \\
\text { atom can interact with other atoms } \\
\text { an unequal number of protons and } \\
\text { electrons creates an ion } \\
\text { different types of atoms have different } \\
\text { susceptibility to losing or gaining an electron } \\
\text { the susceptibility to be ionized can be } \\
\text { predicted by the Periodic Table; metals } \\
\text { tend to lose electrons; non-metals tend } \\
\text { to gain electrons } \\
\text { the way atoms interact can be related to } \\
\text { how easily the atom gains or loses an electron } \\
\text { the way in which atoms interact with each } \\
\text { other can often be predicted from the } \\
\text { Periodic Table }\end{array}$ & $\begin{array}{l}\text { Why do sodium and } \\
\text { chlorine interact to } \\
\text { form } \mathrm{Cl}_{2} \text { and } \mathrm{NaCl} \text { ? } \\
\text { Describe how the } \\
\text { atoms interact with } \\
\text { each other in these } \\
\text { two substances }\end{array}$ \\
\hline
\end{tabular}

district located in a diverse, urban community where approximately half of the students were of low SES $(n=37)$. The other set of students attended a private school located in a diverse, suburban middle- to uppermiddle class community $(n=31)$. The middle school students were in seventh grade. The high school students consisted of two groups, those who were currently taking, or had completed a chemistry course, and those who had not. The middle and high school students were selected to provide a representative sample of a range of educational levels, academic ability and gender when possible. To characterize the upper ranges of the progression, we interviewed a small set $(n=5)$ of undergraduates from a large Midwestern research university, both science and non-science majors. The undergraduates had all completed at least 1 year of high school chemistry. Some were science majors had completed one or more undergraduate-level chemistry courses.

Data Analysis. The data were analyzed using a set of codes designed to track progress in student knowledge of a given concept. The coding scheme was based on Minstrell's (1992) facet approach where each concept from the unpacked construct was broken up into small, independent ideas or "facets" that are readily measurable. See Table 4 for the coding scheme. This approach allowed us to better accommodate all student models and not be predisposed to predefined models. As the interview data were coded, a " 1 " signified the idea/facet was included in the student response, while a code of " 0 " indicated that the idea was not present (see Figure 2 for an example). Responses not included in the coding scheme were coded other. These unexpected responses enrich our research by informing potential instructional strategies to help students move along the HLP. If a question was inadvertently omitted, it was coded NA. Responses were also coded NA if the interviewer strayed too far from the protocol, or inadvertently provided pertinent information to the student.

The first author coded $100 \%$ of the data. A second independent rater coded $10 \%$ of the data that was selected at random. Greater than $95 \%$ agreement was achieved through independent coding.

Building the Progression. For the relevant concepts, the coded data were assembled and sorted into a Guttman scale (Guttman, 1944) in order to characterize the knowledge of individual students. For a 
Table 4

Coding scheme

Atomic Composition and Structure

Does not know

Atoms are spherical

Atoms are made up of components

Atoms contain protons $\left(\mathrm{p}^{+}\right)$

Atoms contain electrons $\left(\mathrm{e}^{-}\right)$

Atoms contain neutrons $\left(\mathrm{n}^{0}\right)$

$\mathrm{p}^{+}$are positively charged

$\mathrm{e}^{-}$are negatively charged

$\mathrm{n}^{0}$ are neutral

Nucleus lies at the center of the atom

$\mathrm{p}^{+}$and $\mathrm{n}^{0}$ make up nucleus

$\mathrm{e}^{-}$on outside of nucleus

Nucleus takes up a small percentage of atomic volume

$\mathrm{e}^{-}$are in orbitals/shells (energy levels)

Certain number of $\mathrm{e}^{-}$allowed in each shell (at each energy level)

Distinguishes between orbitals and shells (energy levels)

Two $\mathrm{e}^{-}$allowed in each orbital

General Inter-Atomic Interactions

A force holds atoms together

An electrical force holds atoms together

$\mathrm{e}^{-}$govern inter-atomic interactions

Type of element determines $\mathrm{e}^{-}$configuration

Outermost $\mathrm{e}^{-}$important in how atoms interact Use octet rule/fill shells

Periodic Table predicts how atoms may interact

Does not know what holds atoms together

Interactions in $\mathrm{Cl}_{2}$ and $\mathrm{NaCl}$ the same
Protons, Neutrons, and Electrons

$\# \mathrm{p}^{+}, \mathrm{n}^{0}, \mathrm{e}^{-}$important

$\# \mathrm{p}^{+}$determines type of element

$\# \mathrm{p}^{+}=\# \mathrm{e}^{-}$in a neutral atom

If $\# \mathrm{p}^{+} \neq \# \mathrm{e}^{-}$, then atom is charged (ion)

$\# \mathrm{p}^{+}$is the atomic number on the Periodic Table

$\# \mathrm{p}^{+}=\# \mathrm{n}^{0}$ not necessary (isotopes)

Mass $\mathrm{p}^{+}$and $\mathrm{n}^{0}$ similar

Mass $\mathrm{e}^{-}$much less than $\mathrm{p}^{+}, \mathrm{n}^{0}$

Electrons

$\mathrm{e}^{-}$move (general)

$e^{-}$do not move

$\mathrm{e}^{-}$moves around the nucleus like planets in solar system (has/implies a trajectory)

$\mathrm{e}^{-}$moves around nucleus within the electron cloud (has/implies a trajectory)

$\mathrm{e}^{-}$behave like both particle and wave

Position and momentum of $\mathrm{e}^{-}$cannot be simultaneously determined

$\mathrm{e}^{-}$movement within electron cloud can only be described by probability

(quantum mechanical—specifies no trajectory)

Covalent and Ionic Bonding

$\mathrm{Cl}_{2}(\mathrm{NaCl})$ formation involves "sharing" pairs of $\mathrm{e}^{-}$ Specifies covalent bond

Ion is a surplus/deficit of electrons

Certain types of atoms have a greater tendency to be ionized

Periodic Table predicts which atoms tend to ionize

Periodic Table predicts what charge the ions will likely be

$\mathrm{NaCl}\left(\mathrm{Cl}_{2}\right)$ formation involves interaction between two oppositely charged atoms

$\mathrm{NaCl}\left(\mathrm{Cl}_{2}\right)$ formation involves "transferring" $\mathrm{e}^{-}$

Atoms with big differences in electronegativity tend to interact through ionic bonds

Specifies ionic bond

Does not know

\begin{tabular}{lc}
\hline Atomic Composition and Structure & \\
\hline idea/facet & code \\
\hline atoms are spherical & 1 \\
\hline atoms are made up of components & 1 \\
\hline atoms contain protons ( $\left.\mathrm{p}^{+}\right)$ & 1 \\
\hline atoms contain electrons (e) & 1 \\
\hline atoms contain neutrons ( $\left.\mathrm{n}^{-}\right)$ & 1 \\
\hline $\mathrm{p}^{+}$are positively charged & 1 \\
\hline $\mathrm{e}^{-}$are negatively charged & 1 \\
\hline $\mathrm{n}^{0}$ are neutral & 1 \\
\hline nucleus lies at the center of the atom & 0 \\
\hline $\mathrm{p}^{+}$and $\mathrm{n}^{0}$ make up nucleus & 0 \\
\hline $\mathrm{e}^{-}$on outside of nucleus & 0 \\
\hline
\end{tabular}

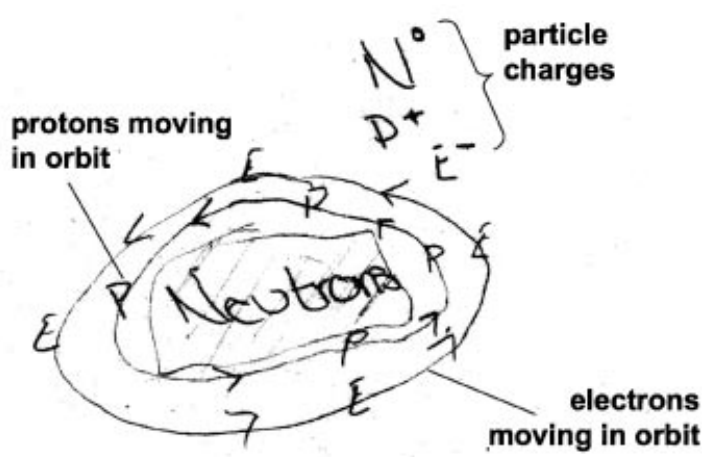

Figure 2. An example of the partial coding for a student's model of atomic structure. 
progression consisting of six successively more complex or sophisticated ideas ordered ABCDEF, the scale is structured such that a student who understands D, also understands ideas A, B, and C, but not necessarily E or F. These scales were used to describe the progression of student understanding, forming individual primary progressions. Significance of each step of the progression was tested using the McNemar test of $2 \times 2$ tables based on the $0 / 1$ scoring by student for two consecutive levels using the MH Program (Uebersax, 2006). It is a test of marginal homogeneity that is a measure of the significance of the difference between the off-diagonal values (McNemar, 1947). A significant difference indicates an ordered connection. See Appendix B for an illustration of this analysis.

Results and Discussion

\section{A Multi-Dimensional Hypothetical Learning Progression}

The first iteration of a multi-dimensional HLP for atomic structure and the electrical forces that govern interactions at the nano-, molecular, and atomic scales is illustrated in Figure 3. Each gray box represents a different level. The levels of the HLP represent sets of ideas that describe a path towards developing a more complex model of matter. Students should select and combine ideas within a level to explain a variety of phenomena related to the structure, properties, and behavior of matter. For example, a Level I model for the structure of a solid would include atoms represented as a sphere without components that are in constant motion. An unspecified force keeps the particles together. At Level III, a students' model would also include a particle model, but would also incorporate knowledge of atoms. Based upon the location of the elements that make up the solid in the Periodic Table, a student should be able to predict the electron configuration and estimate the relative characteristics (e.g., electron affinity, electronegativity, polarizability) to characterize the type of interactions that may occur, which will inform their description of the material

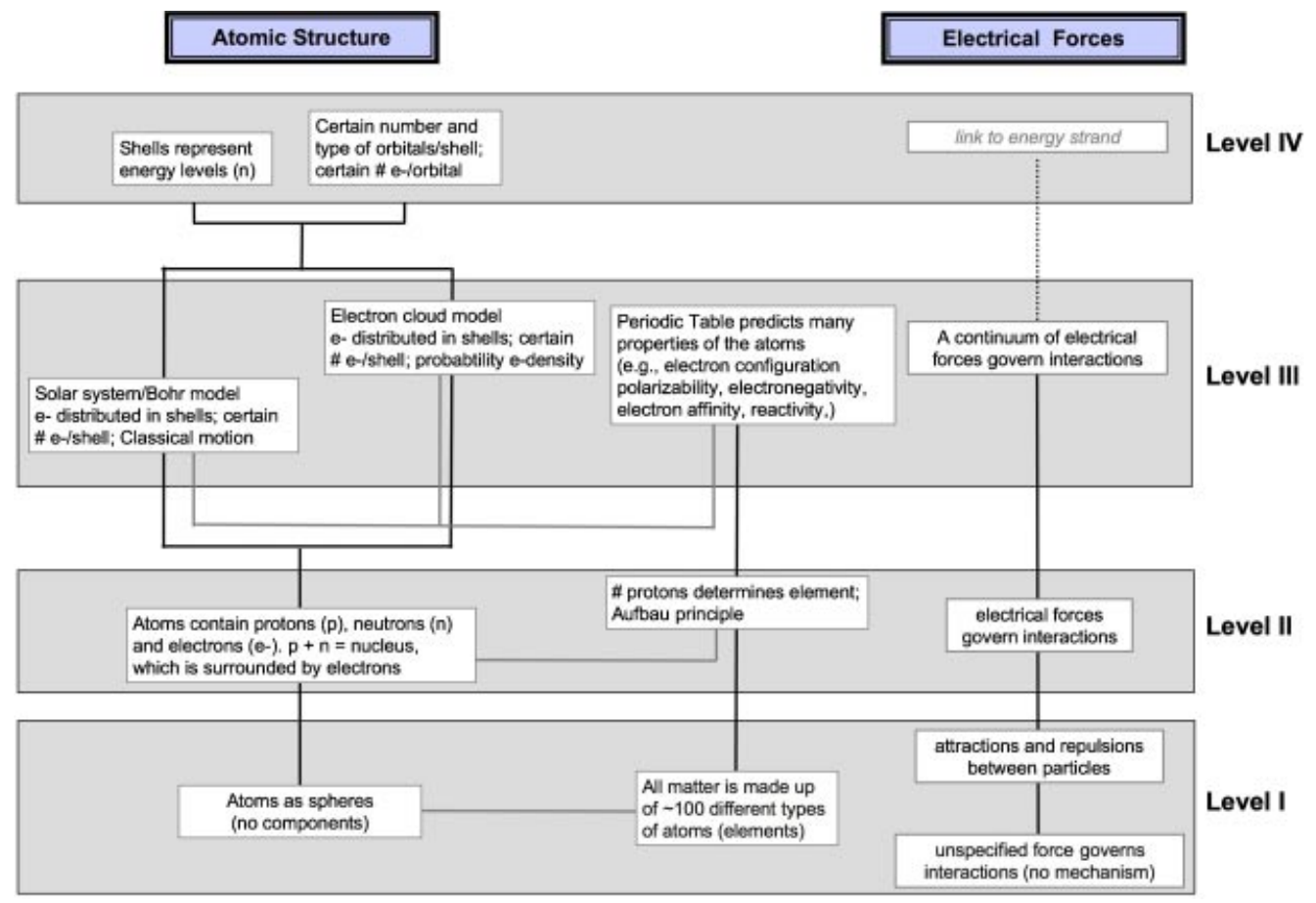

Figure 3. A multi-dimensional hypothetical learning progressions for grades 7-14 for atomic structure and inter-atomic interactions. 
(e.g., ionic lattice, molecules). The interactions between the atoms and molecules will be described in terms of their place on the continuum of electrical forces that govern interactions at that scale. In this way, the levels of the HLP describe increasing levels of sophistication of a model that describes the structure and behavior of matter.

At times, the order in which students learn concepts within a single level may matter, while at other times, the order within a level may be unimportant. Only learning research can answer these questions. However, research has shown that progressing too far in one construct, or strand, before understanding of other concepts at that level has been developed will likely hinder student learning. Details at a level that is too advanced will likely not have meaning to students because they are not connected to other ideas in a useful manner (Roseman, Linn, \& Koppal, 2008). Only information necessary to explain level-appropriate phenomena should be introduced to students (Kedisou \& Roseman, 2002).

The content for the HLPs is represented more thoroughly in Table 5 for atomic structure and Table 6 for electrical forces. In the following sections, we elaborate the content contained within the multi-dimensional HLP, ideas that students may have regarding the content and the connections among ideas students should be able to make when explaining and predicting phenomena and concepts. In addition, we describe the EPs developed for the atomic structure and electrical forces domains based on cross-sectional data. Together with the learning research literature, the EPs inform the potential instructional strategies that may support students in developing conceptual understanding necessary to move from one level of the HLP to the next, and the development of assessments to place students on the HLP.

\section{The Development of Empirical Learning Progressions}

Based upon cross-sectional data, we developed EPs for each of the atomic structure and electrical forces domains. In addition, by sampling sets of students who had experienced different curricula, we obtain a broader picture of students' development in the absence of an LP. We cannot hope to thoroughly characterize students' knowledge structures in a single 30-minute interview. However, the data do provide insight into how students may develop understanding of these important concepts over time and inform the design of potential instructional strategies for helping students move along the progression. While the best way to characterize how students develop knowledge would be to follow them in a longitudinal study, the cross-sectional design provides a useful approximation.

Atomic Structure. Sixty-nine of 73 students fit the EP for atomic structure (see Table 7). Table 5 illustrates the relationship between the HLP and EP. Three of the four who did not fit the EP were able to describe a solar system model (Level 3a) of the atom with the electrons surrounding the nucleus, but could not define the composition of the nucleus as protons and neutrons, usually forgetting the neutrons. The other student described an electron cloud-like model of the atom, but could not recall the names of any of the subatomic particles during this part of the interview. Most ( $>80 \%)$ of the grade 7-14 students in this study possessed some kind of model for an atom. Notably, even after a year of high school chemistry, a significant portion (28\%) of students still held Level 1 or $1 \mathrm{~A}$ models of the atom; this proportion was even higher in a study of 12th grade students' conceptions of atoms and molecules (Griffiths \& Preston, 1992). These results are also consistent with a study that focused on French upper secondary school students, which found that the "atom as a sphere" model was most preferred by students (Cokelez \& Dumon, 2005). However, in that study, as students progressed from grades 10 to 12, they shifted to a Lewis dot representation (elemental symbol and electron pairs). We found no evidence of this trend in our student populations.

Electrical Forces. Another set of interview questions focused on the electrical forces construct. Students were asked to explain the inter-atomic interactions within chlorine $\left(\mathrm{Cl}_{2}\right)$ and sodium chloride $(\mathrm{NaCl})$ and compare them. Based on student drawings and responses to these questions, we built an EP that describes how students currently appear to develop an understanding of the electrical forces that govern these interactions to inform the development of instructional and assessment strategies corresponding to the HLP (see Table 8).

Only 35 students (48\%) attempted to provide an explanation to the questions about inter-atomic interactions; the rest did not know. Some students suggested that the interactions between atoms are due to an 
Table 5

Summary of hypothetical and empirical learning progressions for atomic structure

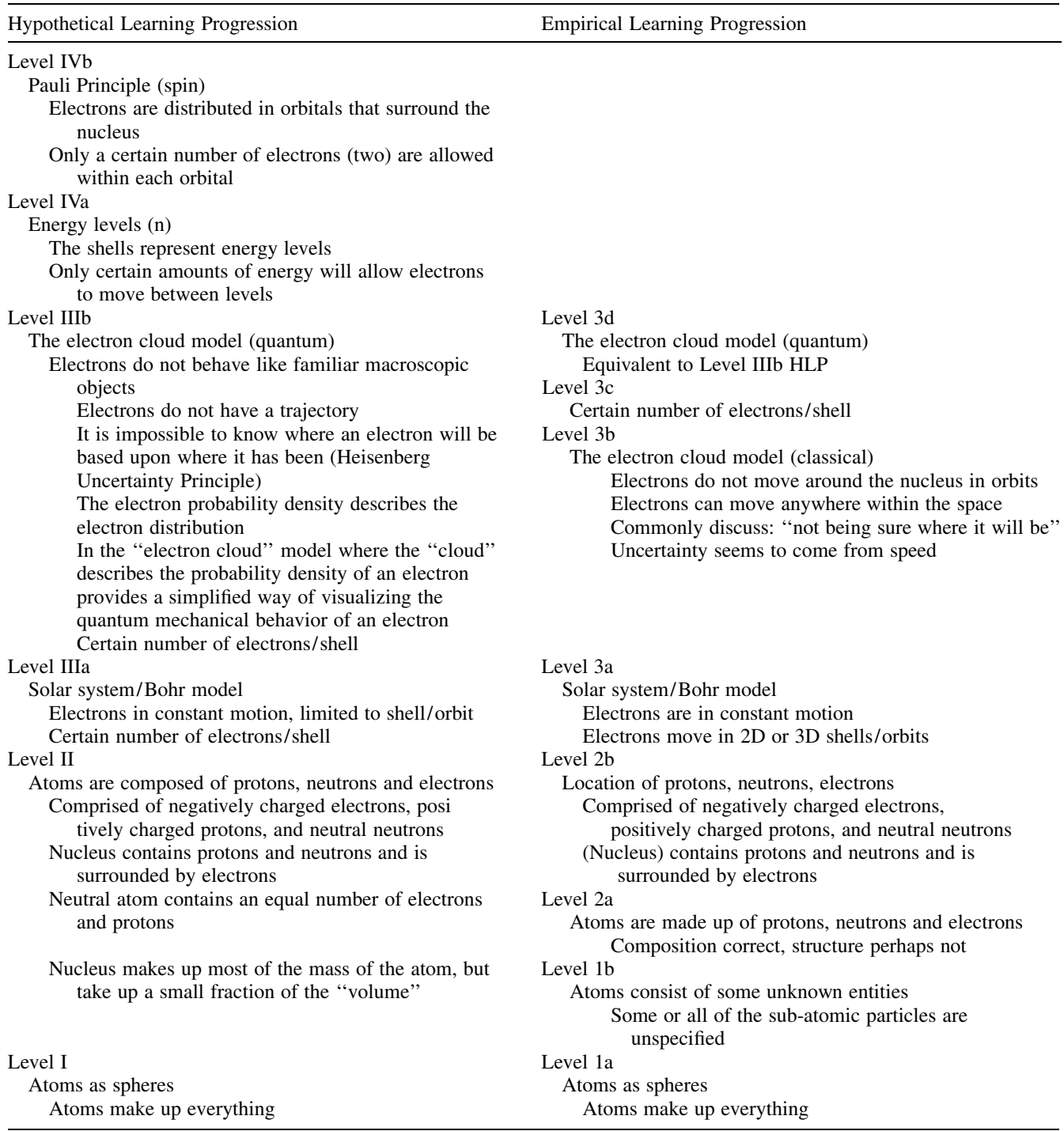

unspecified force, corresponding to the first level of the progression. When students specified a mechanism of the interaction (e.g., electrical force, attraction, and repulsion between particles) the response was defined as Level 2. Very few students occupied these levels. Most of the students at these two levels had not yet incorporated electrons into their models of atoms. Students incorporating electrons into their explanations of the inter-atomic interactions were coded as being at Level 3. A majority of the students who responded to the questions regarding this construct were at Level 3 or above. If students included the idea that the electrons involved in the interactions are in the outermost shell, the response was assigned to Level 4. Approximately half of the students who responded to this question were at this level. If the relationship to the type of element and its place on the Periodic Table was included the students' explanation, it was assigned to Level 5 . Table 6 illustrates the EP and its relationship to the HLP. 
Table 6

Summary of the hypothetical and empirical learning progressions for inter-atomic interactions

\begin{tabular}{|c|c|}
\hline Hypothetical Learning Progression & Empirical Learning Progression \\
\hline $\begin{array}{l}\text { Level V } \\
\text { Importance of environment } \\
\text { Must consider entities involved in interaction, and the } \\
\text { environment }\end{array}$ & $\begin{array}{l}\text { Level } 5 \\
\text { Link to Periodic Table } \\
\text { Groups define electron configuration } \\
\text { Periodic trends }\end{array}$ \\
\hline Level IV & \\
\hline $\begin{array}{l}\text { Continuum of electrical forces } \\
\text { Electrical forces form a continuous scale of bond } \\
\text { strengths } \\
\text { There are different types of inter-atomic interactions, } \\
\text { all governed by electrical forces (e.g., covalent, } \\
\text { ionic, metallic) }\end{array}$ & $\begin{array}{l}\text { Level } 4 \\
\text { Valence electrons } \\
\text { Outermost electrons involved in interactions } \\
\text { The electron configuration affects the type of } \\
\text { interaction that may occur } \\
\text { Reliance on octet model }\end{array}$ \\
\hline $\begin{array}{l}\text { Level III } \\
\text { Interactions governed by electrical forces } \\
\text { Can occur through permanent, localized (static) } \\
\text { charges } \\
\text { Strength of interactions is described by Coulomb's } \\
\text { law; dependent on the amount of charge, distance } \\
\text { between charges, and environment }\end{array}$ & $\begin{array}{l}\text { Level } 3 \\
\text { Electrons govern interactions } \\
\text { No mention of valence electrons despite use of an } \\
\text { octet model } \\
\text { Limited evidence of electrostatic interactions. }\end{array}$ \\
\hline $\begin{array}{l}\text { Level II } \\
\text { Mechanism specified } \\
\text { Attractions and repulsions between particles } \\
\text { Use to explain phenomena }\end{array}$ & $\begin{array}{l}\text { Level } 2 \\
\quad \text { Electrical forces govern interactions } \\
\quad \text { Label only, no mechanism specified }\end{array}$ \\
\hline $\begin{array}{l}\text { Level I } \\
\text { Unspecified force governs interaction } \\
\text { Some kind of attraction between atoms and molecules } \\
\text { May be informal language (e.g., stick together) }\end{array}$ & $\begin{array}{l}\text { Level } 1 \\
\text { Unspecified force governs interaction } \\
\text { Same as HLP Level I }\end{array}$ \\
\hline
\end{tabular}

\section{Defining the Levels of the HLP}

The multi-dimensional HLP depicted in Figure 3 provides a generalized progression that students may follow as they develop a more sophisticated model of matter. In this section, we continue the unpacking process and relate the organization of the content to the learning research literature and the results from our EP to better define the levels of the HLP. Potential instructional strategies to help students' progress to the next level of the HLP are also discussed.

Level I. In middle school, students should be developing a particle model for matter to explain real world phenomena (e.g., water cycle, smells traveling across the room; Merritt, Krajcik, \& Schwartz, 2008; Smith et al., 2006). A basic particle model includes the concept that all matter is made up of particles that are in constant, random motion. It is not uncommon for students to use the terms particle, atom and molecule interchangeably early in the development of their model of matter (Harrison \& Treagust, 1996). Likewise,

Table 7

Learning progression describing how students may develop a basic model of atomic structure

\begin{tabular}{llrc}
\hline Level & \multicolumn{1}{c}{ Description } & $\begin{array}{c}\text { \% Students } \\
\text { (Absolute) }\end{array}$ & $\begin{array}{c}\text { Total no. of } \\
\text { Students }\end{array}$ \\
\hline $3 \mathrm{~b}$ & Electron cloud model & 21 & 15 \\
$3 \mathrm{a}$ & Bohr/solar system model & 18 & 13 \\
$\mathrm{~b}$ & Protons and neutrons are located in the center of the atom, electrons on the outside & 40 & 29 \\
2a & Atoms are made of protons, neutrons and electrons & 48 & 35 \\
$1 \mathrm{~b}$ & Atom contains some components & 68 & 50 \\
$1 \mathrm{a}$ & Atom is a sphere & 85 & 63 \\
0 & Does not know & 14 & 10 \\
& Does not fit on progression & 5 & 4 \\
\hline
\end{tabular}


Table 8

Learning progression describing how students may develop an understanding of electrical forces

\begin{tabular}{llr}
\hline Level & \multicolumn{1}{c}{ Description } & Total no. of Students \\
\hline 5 & The type of element determines the electron configuration & 8 \\
4 & Valence electrons involved in interactions & 18 \\
3 & Electrons mediate interactions & 26 \\
2 & Electrical forces govern interactions & 3 \\
1 & An unspecified force governs interactions & 5 \\
0 & Does not know & 40 \\
& Does not fit on progression & 1 \\
\hline
\end{tabular}

students may use non-scientific language (e.g., stickiness) to describe the forces holding the particles together.

As students develop the concept of an atom, there is no need for a model more complex than a sphere when explaining phenomena using a very basic particle model. However, at this point students can begin developing an understanding of some of the characteristics of atoms. Students should develop an understanding of the atomic scale and its relation to other more accessible scales (e.g., macroscopic, microscopic; AAAS, 1993). They should be able to compare the size of an atom to that of objects that can be easily observed (e.g., a red blood cell, a millimeter). Developing knowledge of atomic scale will ultimately support the idea that gravity is negligible at the atomic and molecular scale, and that electrical forces tend to dominate interactions at that scale. Developing a model for the structure matter brings about the need to consider the factors that define different substances. In particular, students must begin to consider there is a finite number of types of atoms that make up all of matter. The idea of elements is another difficult connection for students. Students may believe that all raw materials are elements (e.g., wool, wood, salt; Driver, Squires, Rushworth, \& Wood-Robinson, 1999).

POTENTIAL INSTRUCTIONAL STRATEGIES. Connecting the macroscopic phenomena to the submicroscopic events is a very difficult and abstract task. Instruction should include developing knowledge and skills about modeling to help students connect their experiences in the macroscale world to what is occurring at the sub-microscopic scale. Students should be required to create (e.g., build, draw) models to explain and predict familiar phenomena. Modeling not only will help students make sense of the abstract content, but also provides a good assessment to measure the development of student understanding. Care should be taken to ensure students do not confuse the model with the actual phenomenon. Instruction should focus on relating the model to the target phenomenon, explicitly considering the aspects that are similar and which are different and linking them to the strengths and limitations of the models (Justi \& Gilbert, 2002).

Since students are commonly introduced to the particle model of matter through phase changes (Franco \& Taber, in press), the idea that particles are in constant random motion is an important part of the model. Even with a model of an atom as a sphere, students can be introduced to the idea that attractive and repulsive forces are involved in this motion. In this model, a particle moves in a linear manner until it approaches another particle. Once the particles get too close to one another, they are repelled and they move away from each other. The idea that electrical forces govern interactions between atoms builds naturally from a model for the structure of a solid and liquid that includes a balance between attraction and repulsion holding the particles together.

Level II. It is unproductive to introduce the details of atomic structure too early. In order to make the composition and structure of the atom meaningful to students, a need for the knowledge must be established (de Vos \& Verdonk, 1996). When comparing the HLP and EP for the atomic structure domain, we found that students did not readily progress to Level II understanding. Students often said that they learned this content in 5th grade- two or more years before the interview. Since at that point in the curriculum students did not have a need for learning about the structure and composition of the atom, it may have lacked meaning to them 
resulting in an inability to integrate the ideas into an organized knowledge structure. As a result, it was common for students' models of atoms to contain some unnamed entities-they had forgotten the details (Level 1a), or list the sub-atomic particles correctly, then forget how they are arranged (Level 2a). In addition, many of the students in our study could locate protons and neutrons at the center of the atom, but did not label it as the nucleus.

During middle school, students commonly begin to explore chemical reactions (Johnson, 2000; Krajcik et al., 2008). They discover that two substances can combine to form a new substance with different properties and learn that everything around them is made from different combinations of slightly more than 100 different types of elements. In particular, they should focus on the approximately 20 elements that make up most of the materials we encounter in our daily lives. Questions arise such as: What is different about each element? Why is it that atoms of certain elements combine and others do not? Why do atoms combine in only certain ways? These questions create a need for introduction to the Periodic Table and a more sophisticated model for the structure and behavior of matter.

In turn, the introduction of the Periodic Table and its trends creates a need for students to develop a model of atomic structure. The number of protons in the atom determines the type of element it is, and defines the atomic number. The protons and neutrons are essentially responsible for the mass of the atoms as electrons have very little mass. The Periodic Table predicts many of the properties of the elements including electron configurations and reactivity.

If the students' models included protons, neutrons and electrons, (Level 2a) they were asked to compare the characteristics of the particles. Connecting the charge to the particle came relatively easily to the students as approximately $62 \%$ of students at Level $2 \mathrm{a}$ on the EP or greater described the charge of all of the components. In contrast, they discussed the relative mass of the particles with much less frequency. In particular, it was more common for them to recall that the mass of the electron was essentially negligible, than the relationship between the masses of the proton and neutron. The lack of emphasis on the relative masses of the sub-atomic particles was also observed in a study of French grade 10-12 students' conceptions of the atom (Cokelez \& Dumon, 2005).

Students at Level 2a and higher were also asked whether the relative number of protons, neutrons and electrons within an atom is important. The students' responses generally followed a coherent progression in relation to the relative number of protons, electrons, and neutrons. The most prevalent response was that the number of protons determines which element it is. Next they integrated the effect the numbers of particles have on the characteristics of the element, in particular, that the number of protons and electrons is equal in a neutral atom, but the number of protons and neutrons does not necessarily have to be equal.

If students have been using a model of attraction and repulsion to describe the interactions between solid spheres (atoms), they can begin to consider the electrical nature of the interactions between atoms once they have developed a model of the atom that contains a positively charged nucleus that is surrounded by electrons. In particular, Coulomb's Law can help students (Levy Nahum et al., 2007) to develop an understanding that the electrical forces depend on the distance between the atoms, their charge and later, the environment in which the interaction occurs.

POTENTIAL INSTRUCTIONAL STRATEGIES. Developing a model for atomic structure is a difficult task. It is made even more difficult because the abstract nature of the content provides little prior knowledge for students to build upon. In this situation, students tend to rely on rote learning because they have no reference to connect the new knowledge to (Tsaparlis, 1997). Therefore, it is important that instruction gives them rich and coherent experiences over a long period of time to help them develop an integrated model that can be built on in further instruction (Caravita \& Halldén, 1994; Schwartz, Weizman, Fortus, Krajcik, \& Reiser, 2008). To help make the model of atomic structure more relevant, it is useful to create a need for the knowledge (de Vos \& Verdonk, 1996). In middle school, it is common to introduce students to the Periodic Table (Ben-Zvi \& Genut, 1998). In high school, to help students understand the arrangement of the elements in the Periodic Table, it is necessary to develop a basic model of atomic structure. Students should be asked to connect atomic structure, in particular the protons and electrons with the elements represented in the Periodic Table. For instance, they should be able to predict the electron configuration for an atom of an element based 
on the Periodic Table. To help students build an understanding of the periodic trends, they should experience some of the differences of the properties of the elements across the rows and down the groups (not including the transition metals, lanthanides, and actinides).

Studies have shown that student understanding is enhanced when they are able to explain the limitations and strengths of a model (Treagust, Harrison, \& Venville, 1996). Thus, developing knowledge and skills related to working with models should continue to be a focus (Harrison \& Treagust, 1996).

When the atom is first introduced to students, a solar system model may be an appropriate representative model as it helps students connect atomic structure, in particular the electron configuration, to the Periodic Table. Although the solar system model is useful, more scientifically accurate models will be introduced later in the curriculum. Therefore, if the instructor chooses to introduce this model, it is especially important for students to consider the various representations of the atom as models in order to prepare them for later learning. Learning research should examine whether other models of atomic structure would better support future learning.

At the previous level, students developed a model for the mechanism of the interactions between particles. The next step is to introduce the nature of electrical forces to students. From everyday experiences, students should be familiar with static electricity. Building upon that knowledge, students can explore a range of macroscopic phenomena (e.g., a balloon sticking to the wall, pith balls attracting and repelling each other, moving a stream of water with a charged rod) to develop an understanding of the basic rules of electrical charges. They can see that certain charges repel each other, while other attract each other. They can experience induction, through phenomena such as a comb that has been charged picking small up pieces of paper. Instruction should focus not only on rules of attraction and repulsion, but also the dependence of the electrical force on the distance between the two objects (Coulomb's law). Only after students understand the concept of electrical charge should they connect the phenomena to the atomic level. At that point students should differentiate between neutral atoms of the elements on the Periodic Table and ions, which have an excess or deficit of electrons in relation to the number of protons. Finally, students can begin to explain the macroscopic phenomena using atomic/molecular explanations.

To support the idea of electrical charges, students should experience a variety of models that represent the attractive and repulsive phenomena. Computer simulations have been show to be useful in supporting students in developing understanding of these abstract phenomena (Frailich, Kesner, \& Hofstein, in press). In particular, if students explore the rules of electrical attraction and repulsion with simulations before introducing the scientific terminology (e.g., atoms, ions), evidence suggests that they develop a deeper understanding of the forces that govern the interactions (Pellegrino, Krajcik, Shipley, et al., 2008). If students have the opportunity to simulate a multitude of different conditions and test variables, and then relate the simulations to a selection of real life experiences, they should be able to develop better understanding of the relationship between atomic structure, the characteristics predicted by the Periodic Table and the electrical forces.

Level III. Level II provided students with a model of the atom that helps them navigate and begin to develop an understanding of the predictive power of the Periodic Table. Level III extends the model of atomic structure to further explore the trends of the Periodic Table and prepare students to develop explanations for the interaction, or bonding, of atoms.

The idea of electrons being distributed in shells around the nucleus, with only a certain number of electrons allowed in each shell connects to the idea of valence electrons. A solar system or Bohr model of the atom is sufficient to develop understanding of these ideas. With this model, students are prepared to consider chemical bonding and ions. Explaining phenomena such as interactions between polar molecules and how neutral molecules such as the noble gases interact through electrical attractive forces requires an electron cloud model, where the electron density is described in terms of probability. In order to use this model, students must also understand probability. Again, the characteristics of each model of atomic structure should be made clear and differentiated for students.

Our EP suggests that the Bohr, or solar system model may be more useful than the electron cloud model for helping students connect certain important aspects of the atomic model. We found that holding a solar system model of the atom appeared to help students integrate the idea of shells into their atomic models. Eighty-five percent of the students with a solar system model also described the electrons as being distributed 
in shells, whereas only $33 \%$ of the students with the more scientifically accurate electron cloud model used shells in their descriptions. This difference may be due to the fact that the shells are almost inherent to the solar system model, but much more difficult to visualize and represent for the more abstract electron cloud model. Even when using the term electron cloud to describe electron distribution, students often relied on orbitals in their representations of atoms, but verbally volunteered that the electrons are not really in orbitals as drawn. In another study, students provided similar models depicting orbitals with an electron cloud label (Unal \& Zollman, 1999). Therefore, part of students' difficulties may lie not only in developing a quantum mechanical model of atomic structure, but also communicating the abstract model. Research efforts are needed to develop ways to assess students' ideas about atomic structure.

A majority of the students who incorporated electrons into their explanation of inter-atomic interactions (Level 3 or higher on the EP) described the atoms as wanting or needing to fill the shell or "make eight." This is consistent with previous research, which has shown that students often rely heavily on the octet rule as an explanatory framework to explain how atoms interact (Taber, 1998; Taber \& Coll, 2002). While useful for explaining and predicting certain phenomena, using this kind of framework to explain bonding can limit students' progress (Levy Nahum et al., 2007). The students seemed to use the octet framework algorithmically, using the idea of filling shells, but not always considering what was really happening to the electrons.

Based upon the McNemar tests, the only idea that was consistently required in the students' models of covalent and ionic bonding was that electrons govern the interactions between atoms. Although they were given a Periodic Table, students rarely incorporated information from it into their explanations. For instance, it was almost as common for students to describe the interactions between atoms in $\mathrm{NaCl}$ as occurring solely through shared electrons (covalent bonding) as for them to correctly describe the electrostatic interactions involved in ionic bonding. The students' ideas appear to be widespread because students from different populations following different curricula exhibited this same confusion. However, these results contrast with those of Coll and Treagust (2001) where secondary and undergraduate students strongly preferred an electrostatic model to describe ionic bonding. Taber (2001a) found that college-level chemistry students often began with an octet explanatory framework, but incorporated an electrostatic model in their explanations of bonding after directed instruction.

When predicting and explaining how different types of atoms might interact with each other, students should make connections to atomic structure and information drawn from the Periodic Table. Electron affinity (the amount of energy needed to remove an electron from an ion with a charge of $[-1])$ differences help predict the degree of ionic or covalent character of a bond. The number of covalent bonds in which an atom can participate can also be predicted by the Periodic Table. The extent to which an atom attracts electrons (i.e., electronegativity) should be used to predict the presence and relative strength of a dipole moment within a molecule. This requires that they hold an electron cloud model for the distribution of electrons in an atom. To ensure students incorporate these ideas into their models of inter-atomic interactions, it is important to develop assessments that not only ask how a set of atoms interacts the way they do, but why they interact that way. At this level, students should be able to explicitly refer to specific models in their explanations, and justify their choice of model for the particular situation.

In our EP, the idea that electrons are distributed in shells appears to connect to the primary progression for atomic structure from Level $3 \mathrm{a} / \mathrm{b}$. Students did not incorporate any quantum ideas into their discussion of shells. Approximately $25 \%$ of the students that described electrons as being distributed in shells went on to designate a correct number of electrons that can be contained within each shell. Only one student (high school) differentiated orbitals and shells by drawing $s$ (spherical) and $p$ (figure eight) orbitals that he was not able to explicitly name. Otherwise, students seemed to use the terms shell and orbital interchangeably, which is a common error (Taber, 2002). Although students at this level are expected to begin integrating ideas related to shells and orbitals, and the number of electrons allowed in each into their atomic models, we found that grade 7-14 students typically did not integrate most of these ideas into their atomic models, particularly when describing atomic structure. This is consistent with the findings of a study where Greek 12th grade students did not develop good understanding of orbitals or the probabilistic nature of electrons (Tsaparlis \& Papaphotis, 2002). 
Over-reliance on a single model may hinder the formation of an integrated knowledge structure of this complex content. For example, while Lewis dot structures are useful ways of communicating the interactions, they facilitate a dependence on the octet model and students may lose focus of the phenomenon the model is representing. In a study of grade 10-12 students, Cokelez and Dumon (2005) observed that students tended to use Lewis dot structures instead of the more traditional atomic models as their preferred representation of atoms after studying chemical bonding. Based upon results from our study, this may mean that students do not understand the phenomenon that occurs when a chemical bond is formed. For instance, a high-achieving high school chemistry student from our study applied the octet rule and used Lewis dot structures to describe covalent and ionic bonding between what he called "elements," but had a model of atoms as solid spheres. The symbols in his Lewis structures represented elements; his knowledge was compartmentalized. As he did not connect the elements in these structures to atoms, he really did not understand the phenomena. This example illustrates the need for consideration of how ideas within HLPs connect and branch, in order to support students in developing integrated knowledge structures.

POTENTIAL INSTRUCTIONAL STRATEGIES. Students often favor the solar system model of an atom. Because students seem reluctant to give up the solar system model of the atom, some argue that the Bohr model hinders students' development of more accurate atomic models (e.g., Fischler \& Lichtfeld, 1992). However, a quantum mechanical model is not necessary to explain all phenomena. The solar system model is useful for developing an understanding of concepts such as the Periodic Table, electron configurations and certain types of chemical bonding. Scientists often choose to utilize different models and characterize properties differently depending on the problem; it might be a useful strategy for students to do the same. However, it takes time for students to develop a quantum mechanical model. For example, over the course of a 16-week unit, a grade 13 student began with a solar system model and progressed through several more scientifically accurate models (Petri \& Niedderer, 1998).

New ideas are often presented to students superficially and in an abstract manner, which prevents them from organizing and connecting them to previous knowledge (Resnick, 1983). To them, the different models for atomic structure may represent completely different ideas rather than a different model that explains the same phenomenon. What is more important, however, is that students need to realize that more advanced models can explain phenomena previous models could not. Evaluations of high school chemistry textbooks found that the historical representation of the development of the quantum mechanical model of atomic structure, the process of the paradigm shift was not well represented (Niaz, 1998; Shiland, 1997). There was little discussion of the limitations of previous models that drove scientists to modify the existing models of atomic structure, and discussion of the reasoning that scientists used to change the model was rare. Thus, these ideas, as with much of science, are taught as a series of established conclusions so students never gain an understanding of the need for quantum mechanics and the limitations of classical physics.

When students experienced curricula that placed an emphasis on contrasting models, student learning of the quantum model was not hindered by the inclusion of the Bohr model (McKagan, Perkins, \& Wieman, 2008). Another curriculum that emphasized models, in particular the juxtaposition of the Bohr and quantum models of the atom and presented them as two completely independent frameworks, also had some success in resolving these issues (Kalkanis, Hadzidaki, \& Stavrou, 2003). However, in order for both models to be useful and productive for students, it is important to emphasize their roles as models that represent certain aspects of the atom well, and others not as effectively (Taber, 2001b). As students work to develop a quantum mechanical model of the atom, they should experience a variety of activities and models (physical and computer) that illustrate what it means for electron density to be described by probability.

Connecting the history of science to the strengths and limitations of scientific models was shown to be an effective instructional strategy for helping students to use the Periodic Table and its related trends as a model instead of a table of facts (Ben-Zvi \& Genut, 1998). When first introduced, students often apply the periodic trends in an algorithmic manner. However, after instruction on how historically such application of the periodic trends resulted in errors, students began to critically evaluate how they utilized the information predicted by the Periodic Table. 
In addition, research has shown that student understanding of inter-atomic interactions can be enhanced by interacting with computer simulations (Frailich et al., in press). Technology learning tools may also be useful strategies for providing students with experiences that illustrate the periodic trends.

In sum, to help students connect the phenomena to the various representations, instruction should also focus on the use of models. Students should be regularly required to explain what different models mean. They should be able to represent bonding phenomena in multiple ways and explain the strengths and limitations of each representation. This will help them build an integrated knowledge structure that connects models to the phenomena.

An alternative pedagogical approach for instruction on chemical bonding involves shifting the focus from classifications (e.g., ionic, covalent) and sets of rules (e.g., octet rule, electronegativity differences) to the characteristics that are common to all chemical bonds (Levy Nahum et al., 2007). While the bonding categories provide convenient benchmarks that help describe how electrons mediate interactions, they may hinder the development of conceptual understanding. For instance, an ionic bond always has some covalent character. Traditional instruction often leads students to consider covalent and ionic bonding in a dichotomous manner, when in fact there is a continuum of chemical bonds that have varying degrees of covalent and ionic character (Levy Nahum et al., 2007; Taber \& Coll, 2002). Ionic interactions build directly from the Level II ideas that interactions among atoms and molecules are governed by electrical forces, the strength of which depends on charge and the distance between the interacting entities. Focusing on the electrostatic interactions between ions (ionic interactions) builds directly from these ideas. Students can connect the trends for electron affinity with those of electron configuration from the Periodic Table to make predictions about the interactions in ionic solids. Placing instruction of the electrostatic interactions first provides students with a model for bonding that does not necessarily rely on the octet model. Only after students have developed a model for interactions based on electrical forces should they be introduced to covalent bonding. By providing a coherent mechanism to explain the continuum of electrical forces that govern interactions between atoms and molecules, students can more easily organize and integrate the concepts into their knowledge structures, allowing them to apply these concepts to a range of phenomena.

NSE is interdisciplinary in nature, as are most emergent sciences. Contemporary learning theories stress the importance of connected knowledge, therefore, it is important to make the knowledge students develop more flexible such that they can make connections among concepts from multiple disciplines. Different disciplines often use different terms to describe the same phenomena, which often confuses learners (Nakhleh, 1992). It is important for instructors to make the connection among the terminology of various disciplines to help students reconcile the apparent contradiction. In this case, it may be useful to emphasize the electrical nature of inter-atomic interactions - that chemical bonds are a type of electrical force (Levy Nahum et al., 2007). For example, biologists term the interactions between oppositely charged functional groups "salt bridges." In chemistry, interactions between ions of opposite charge are called ionic bonds. Both of these phenomena are examples of ionic interactions. Considering interactions of nano-, molecular, and atomic scale entities from all disciplines in terms of the same electrical forces may make it easier for students to develop the connections needed to develop conceptual understanding of interdisciplinary science.

Level IV. There are certain ideas that are fundamental to the quantum mechanical model of atomic structure: wave/particle duality, uncertainty, quantization of energy levels and spin (i.e., Pauli Principle) that can be introduced to upper secondary students in a qualitative manner (Stevens et al., in press). In our EP, we found that only one student had a truly probabilistic model for the structure of the atom saying, "[E]lectrons I, I guess jumping - I think, I think they said in quantum physics it was like jumping in and out of existence ..." (\#0088). However, in another part of the interview, when he was explaining his model of atomic structure, he described the electron motion saying, "they travel in circles, and also in like crazy figure eights ... they go in three dimensions ... there's a bunch of different ways they travel, like paths. One's just a circle ..." (\#0088). The latter description is more consistent with classical motion, which suggests that his quantum mechanical model is not fully integrated into his model of atomic structure. Students who used an "electron cloud" model, typically did not discuss electrons in terms of probability or electron density. A few students introduced the idea of probability into their models discussing that there is no way to predict exactly where the 
electrons are, but maintained language consistent with classical mechanics when describing electron motion (e.g., floating, zooming around). It is not uncommon for students to struggle to make sense of the relationship between quantum and classical models (Cervellati \& Perugini, 1981; Kalkanis et al., 2003; McKagan et al., 2008).

These are difficult, non-intuitive concepts. Because they are so removed from real life experiences, students need an extended time to develop a knowledge structure that accommodates these ideas. For example, after experiencing 4-20 lessons within an advanced physics course, upper secondary students were not able to develop a good understanding of wave-particle duality or uncertainty (Olsen, 2002). However, Petri and Niedderer (1998) found that most high school students were able to add some quantum mechanical models to their repertoires after 16 weeks of instruction, but still preferred the solar system model of the atom except in specific circumstances. While some students did not progress at all from the solar system model, this may be because they did not understand the utility of the more complex model - that it could explain phenomena that the simpler models could not. Further learning research is necessary to identify successful pedagogical strategies for supporting the development of conceptual understanding of the different models of atomic structure.

In order to fully characterize the interactions at the nano-, atomic, and molecular scales, students must consider the environment of the interacting entities and the energy. This is essential for understanding phenomena like the hydrophobic effect (e.g., protein folding, membrane formation). These ideas will be addressed more completely when the energy strand is added to the progression.

POTENTIAL INSTRUCTIONAL STRATEGIES. Quantum mechanical ideas do not coincide with our everyday experience. In addition, quantum mechanics becomes more important for explaining and predicting the behavior of matter at scales too small to experience directly. Therefore, models continue to be a critical aspect of instruction for this abstract content. Computer models and simulations may be particularly useful for helping students to develop an understanding of quantum mechanical concepts and phenomena.

Although quantum mechanical ideas are commonly introduced in upper high school and lower undergraduate science courses in a qualitative manner, they are still difficult for students to conceptualize (Ireson, 2000; Stefani \& Tsaparlis, in press). Ke, Monk, and Duschl (2005) suggest providing students experience with related phenomena such as several forms of standing waves (linear, closed loop, a twodimensional surface) and diffraction patterns from light and electrons to help them to develop an understanding of quantum mechanical concepts. However, these experiences do not help students understand the vast difference between the classical and quantum mechanical worlds, which is an important part of developing an understanding of the two models. Employing nanoscale phenomena may provide this connection for students. For instance, quantum dots are nanoscale materials that are confined in all three dimensions. Like molecules, they have quantized energy levels. The color of the light they emit is related to the space between the energy levels. This provides students with a property visible on the macroscopic scale that connects to an important quantum mechanical concept. The transition of a metal from a conductor to a semi-conductor to an insulator is another phenomenon that is related to quantum confinement. It provides a real example of the difference between (essentially) continuous and quantized energy levels. The phenomena that are traditionally used to illustrate quantum mechanical concepts are often extremely abstract themselves (e.g., blackbody radiation, the photoelectric effect). Choosing phenomena that students can relate to in some way provides them with an opportunity to see the usefulness of the quantum mechanical model.

Educational research related to teaching and learning quantum mechanics is relatively limited. Quantum effects have been identified as one of the big ideas of NSE for grade 7-12 students (Stevens et al., in press). If it is indeed deemed a priority for students to develop a qualitative understanding of quantum mechanical principles, room must be made in the curriculum. Usually, the fundamental ideas are taught quickly and all at once, often in a single chapter. A much more extensive amount of time must be devoted to instruction related to these difficult and complex concepts. However, just more time is not enough; learning research must focus on questions such as, which ideas should be taught first, what phenomena are accessible to students and useful for instruction, what types of pedagogical strategies can help students to develop an understanding of the content before students can uniformly develop understanding of quantum mechanical concepts. In addition, 
research must ascertain whether students have the appropriate prerequisite knowledge (e.g., energy, light) to build upon. The development of materials that correspond to the HLPs of atomic structure and electrical forces will help learners build more integrated understandings of these areas and will perhaps allow more students to develop understandings of quantum mechanical concepts.

\section{Summary}

We have presented a multi-dimensional HLP that describes potential routes for students to develop understanding of two constructs critical for developing understanding of several of the big ideas of NSE (Stevens et al., in press), atomic structure and the electrical forces that govern interactions at the nano-, molecular, and atomic scales. Also included are the connections to the Periodic Table and the characteristics of the different types of atoms that it predicts. The HLP specifies the connections students should be able to make between ideas within and across these big ideas.

We followed a systematic design approach, CCD (Pellegrino, Krajcik, Stevens, et al., 2008), to ensure that the science content contained within the critical concepts aligned with all aspects of the HLP throughout the development and refinement process. The same process will be instrumental in the development of curriculum materials and assessments associated with the HLP. In addition, we have described methodology for developing an EP based upon student data. Together, this methodology will continue to support the iterative process of refining and empirically testing the HLP.

There are several instructional strategies that are common to helping students move along the HLP. Students should only be introduced to new information when it is needed to explain a phenomenon or concept in order to make the new knowledge meaningful. In addition, instruction should focus on models and modeling to facilitate students' connections between the macroscopic and atomic scale phenomena. Both instruction and assessment should focus on the connections across ideas to support the development of integrated knowledge structures.

\section{Implications and Conclusion}

This study describes work towards developing and empirically testing the sequence and assumptions behind an HLP for atomic structure and the electrical forces involved in interactions at the nano-, molecular, and atomic scales. This multi-dimensional HLP extends the LP for the atomic molecular theory for K-8 students previously proposed by Smith et al. (2006), defining the sets of ideas that lead to more sophisticated understanding of the structure and behavior of matter. This HLP represents only a portion of the content for the nature of matter. In the future, constructs related to the particle model of matter, materials and energy will be incorporated. A complete HLP for the nature of matter will describe potential routes for students to build understanding of ideas that lie at the foundation of an extensive range of phenomena and concepts from multiple scientific disciplines (e.g., chemical reactions, formation of cell membranes, mineralization processes, the carbon cycle). Different combinations of ideas will help students explain different phenomena. Thus, this multi-dimensional HLP is not limited to NSE or chemical education, but also informs curricular organization for many disciplines.

This HLP builds on the hypothesis that developing conceptual understanding of just a few key ideas (Duschl et al., 2007; Smith et al., 2006) and helping students make connections between the ideas will help them develop an integrated knowledge structure that allows them to apply their knowledge to a range of new situations (Ausubel, 1968; Linn et al., 2004; Taber, 2001b). The resulting multi-dimensional HLP describes not only the content that students must understand as they develop more sophisticated knowledge of the discipline, but also illustrates the sets of ideas they must be able connect to explain phenomena in a levelappropriate way.

NSE, like most emergent science, is interdisciplinary in nature, which requires knowledge in separate disciplines to be connected in new ways. Because NSE is the merging of all scientific disciplines at the nanoscale, the ability to make new connections becomes even more important. For example, electrical forces play a key role in the explanation both of chemical and nanoscale phenomena. They govern the chemical bonds that make up individual molecules, covalent networks, and ionic lattices. The same principles that 
describe the phenomena related to chemical bonding also govern the interactions of nanoscale structures that maintain and regulate life (e.g., DNA double helix, protein folding, biomolecular recognition). Thus, an HLP that illustrates the connections between ideas that are needed to explain relevant phenomena must be a critical part of introducing emergent science into the curriculum.

Our empirical work and that of others (e.g., Taber, 2000) show that most students lack the level of understanding that allows them to flexibly use their knowledge and apply it to new problems. In particular, we find that there is limited evidence for the development of integrated knowledge structures, which suggests that students will have difficulty applying their knowledge when learning new concepts, in particular those that are part of emergent science such as NSE. This suggests that new and coherent approaches to learning and teaching these important concepts must be developed, tested, and implemented to help students build integrated knowledge structures to ready them for new ideas in science. A multi-dimensional HLP that describes the development of such integrated knowledge structures is an important first step towards developing instructional materials and assessments that support this type of learning.

The use of relatively large grain-sized levels to help define and organize the science content of important, complex concepts (i.e., big ideas in science) can be useful in the first step of the development of HLPs to ensure coherence over time. The development and refinement of an HLP is an iterative process that is informed by empirical testing of specific instructional experiences designed to help students move from one point to another on the progression. While longitudinal studies or teaching experiments would be the idea way to empirically test an LP (Duschl et al., 2007), there are many challenges to such studies. A more practical approach is to consider smaller steps that explicitly specify a series of learning goals that describe how to help students move from one level of the progression to the next. These smaller steps are similar to learning trajectories, a construct that has been employed by the mathematics education community to organize instruction of important ideas in the discipline (Gravemeijer, 2004; Simon \& Tzur, 2004). They include the "consideration of the learning goal, the learning activities, and the thinking and learning in which students might engage" (Simon, 1995, p. 133) as they develop understanding of the desired content. Learning trajectories include specific strategies to support student learning that are intended to be adapted by classroom teachers to suit the needs of their students (Clements \& Sarama, 2004). Thus, a hypothetical learning trajectory (HLT) or sets of HLTs specifically describe how students may move from one level to the next on the HLP. The methodology we created to develop progressions of ideas (i.e., EPs) that describe how students build understanding of important ideas as they move through the curriculum (first iteration), or experience instruction based upon an HLT (later iterations) will play an important role throughout the process of development, refinement and empirical testing of the HLP.

The emphasis on making the connections of ideas both within and among domains in this HLP requires a new approach to the development of instructional materials. The current approach tends to consist of individual units that stand alone and do not help students make the connections needed to build integrated knowledge structures. For example, a review of major middle school science textbooks revealed that they did not focus on achieving appropriate learning goals and lacked coherence across time and disciplines (Kedisou \& Roseman, 2002). Often coverage of important, foundational ideas was intermingled with unnecessary details and unrelated concepts. Instead of this disjointed approach, we need curricular coherence, which requires the development of curriculum materials that not only contain a complete and logical presentation of the content, but also specify the connections between interrelated ideas within that content (Roseman et al., 2008). Such materials blended with appropriate instruction will help students build their understanding over time by presenting situations that provide opportunities for students to make connections.

As we work to empirically test this multi-dimensional HLP, HLTs that describe specific instructional strategies to move students from one level to the next on the HLP must be developed. To maintain the coherence of the HLP, the HLTs must be anchored in learning goals that provide logical connections to both prior and future learning. The HLTs must help students make the connections required for building an integrated knowledge structure related to the nature of matter through both inter-unit and intra-unit coherence (Shwartz et al., 2008). Only by using such materials will we succeed in helping students build integrated understanding such that they can apply it to a variety of new situations. 
We would like to thank Molly Yunker and Kelly Hutchinson for their help with data collection and Namsoo Shin and Jim Pellegrino for helpful discussions throughout the development process. We also thank the Center for Statistical Consultation and Research at the University of Michigan for their consultations. This research was supported by the National Science Foundation through the National Center for Learning \& Teaching in Nanoscale Science and Engineering (NCLT) grant no. 0426328 and by grant no. 0822038 . Any opinions, findings, and conclusions or recommendations expressed in this material are those of the authors. Preliminary analysis of this work was presented at the 2007 National Association for Research in Science Teaching Conference in New Orleans, LA and the 2007 American Educational Research Association in Chicago, IL.

\section{References}

American Association for the Advancement of Science. (1993). Benchmarks for Scientific Literacy. New York: Oxford University Press.

Atkins, P., \& Jones, L. (1997). Chemistry: Molecules, matter, and change (3rd ed.). New York: W.H. Freeman and Company.

Ausubel, D.P. (1968). Educational psychology: A cognitive view. New York: Holt, Rinehart and Winston, Inc.

Baroody, A.J., Cibulskis, M., Lai, M.-1., \& Li, X. (2004). Comments on the use of learning trajectories in curriculum development and research. Mathematical Thinking and Learning, 6(2), 227-260.

Ben-Zvi, N., \& Genut, S. (1998). Uses and limitations of scientific models: The Periodic Table as an inductive tool. International Journal of Science Education, 20(3), 351-360.

Bransford, J.D., Brown, A.L., \& Cocking, R.R. (2000). How People Learn: Brain, mind, experience, and school. Washington, DC: National Research Council.

Caravita, S., \& Halldén, O. (1994). Re-framing the problem of conceptual change. Learning and Instruction, 4, 89111.

Cervellati, R., \& Perugini, D. (1981). The understanding of the atomic orbital concept by Italian high school students. Journal of Chemical Education, 58(7), 568-569.

Chi, M.T.H., Feltovich, P.J., \& Glaser, R. (1981). Categorization and representation of physics problems by experts and novices. Cognitive Science, 5(2), 121-152.

Clements, D.H., \& Sarama, J. (2004). Learning trajectories in mathematics education. Mathematical Thinking and Learning, 6(2), 81-89.

Cokelez, A., \& Dumon, A. (2005). Atom and molecule: Upper secondary school French students' representations in long-term memory. Chemistry Education: Research and Practice, 6(3), 119-135.

Collins, A., Joseph, D., \& Bielaczyc, K. (2004). Design research: Theoretical and methodological issues. The Journal of the Learning Sciences, 13(1), 15-42.

Coll, R.K., \& Treagust, D.F. (2001). Learners' mental models of chemical bonding. Research in Science Education, 31, 357-382.

de Vos, W., \& Verdonk, A.H. (1996). The particulate nature of matter in science education and in science. Journal of Research in Science Teaching, 33(6), 657-664.

diSessa, A.A. (1988). Knowledge in pieces. In: G. Forman \& P.B. Pufall (Eds.), Constructivism in the computer age (pp. 49-70). Hillsdale, NJ: Lawrence Erlbaum Associates.

Driver, R., Squires, A., Rushworth, P., \& Wood-Robinson, V. (1999). Making sense of secondary science: Research into children's ideas. London: Routledge.

Duschl, R.A., Schweingruber H.A., Shouse A. (Eds.). (2007). Taking science to school: Learning and teaching science in grades K-8. Washington, D.C.: National Academy Press.

Fischler, H., \& Lichtfeld, M. (1992). Modern physics and students' conceptions. International Journal of Science Education, 14(2), 181-190.

Franco, A.G., \& Taber, K. (in press). Secondary students' thinking about familiar phenomena: Learners' explanations from a curriculum context where 'particles' is a key idea for organising teaching and learning. International Journal of Science Education.

Frailich, M., Kesner, M., \& Hofstein, A. (2009). Enhancing students' understanding of the concept of chemical bonding by using activities provided on an interactive website. Journal of Research in Science Teaching, 46(3), 289-310.

Gravemeijer, K. (2004). Local instruction theories as means of support for teachers in reform mathematics education. Mathematical Thinking and Learning, 6(2), 105-128.

Griffiths, A.K., \& Preston, K.R. (1992). Grade-12 students' misconceptions relating to fundamental characteristics of atoms and molecules. Journal for Research in Science Teaching, 29(6), 611-628.

Guttman, L. (1944). A basis for scaling qualitative data. American Sociological Review, 9(2), 139-150. 
Harrison, A.G., \& Treagust, D.F. (1996). Secondary students' mental models of atoms and molecules: Implications for teaching chemistry. Science Education, 80(5), 509-534.

Harrison, A.G., \& Treagust, D.F. (2002). The particulate nature of matter: Challenges in understanding the submicroscopic world. In: J.K. Gilbert, O.D. Jong, R. Justi, D.F. Treagust, \& J.H. Van Driel (Eds.), Chemical education: Towards research-based practice (pp. 189-212). Dordrecht, Netherlands: Kluwer Academic Publishers.

Ireson, G. (2000). The quantum understanding of pre-university physics students. Physics Education, 35(1), 15-21.

Johnson, P. (2000). Children's understanding of substances. Part 1: Recognizing chemical change. International Journal of Science Education, 22(7), 719-737.

Justi, R., \& Gilbert, J. (2002). Models and modelling in chemical education. In: J.K. Gilbert, O.D. Jong, R. Justi, D.F. Treagust, \& J.H. Van Driel (Eds.), Chemical education: Towards research-based practice (pp. 47-67). Dordrecht, Netherlands: Kluwer Academic Publishers.

Kalkanis, G., Hadzidaki, P., \& Stavrou, D. (2003). An instructional model for a radical conceptual change towards quantum mechanics concepts. Science Education, 87, 257-280.

Ke, J.-L., Monk, M., \& Duschl, R. (2005). Learning introductory quantum physics: Sensori-motor experiences and mental models. International Journal of Science Education, 27(13), 1571-1594.

Kedisou, S., \& Roseman, J.E. (2002). How well do middle school science programs measure up? Findings from Project 2061's curriculum review. Journal of Research in Science Teaching, 39(6), 522-549.

Krajcik, J., McNeill, K.L., \& Reiser, B.J. (2008). Learning-goals-driven design model: Developing curriculum materials that align with national standards and incorporate project-based pedagogy. Science Education, 92(1), 1-32.

Krajcik, J., Shin, N., Stevens, S.Y., \& Short, H. (April, 2009). Using Learning Progressions to Inform the Design of Coherent Science Curriculum Materials. Paper presented at the American Educational Research Association, San Diego, CA.

Lee, K.-W.L., \& Tan, S.-N. (2004). Atoms and molecules: Do they have a place in primary science? Primary Science Review, 82, 21-23.

Levy Nahum, T., Mamlock-Naaman, R., Hofstein, A., \& Krajcik, J. (2007). Developing a new teaching approach for the chemical bonding concept aligned with current scientific and pedagogical knowledge. Science Education, 91, 579-603.

Linn, M.C., Eylon, B.-S., \& Davis, E.A. (2004). The knowledge integration perspective on learning. In: M.C. Linn, E.A. Davis, \& P. Bell (Eds.), Internet environments for science education (pp. 29-46). Mahwah, NJ: Lawrence Erlbaum Associates.

Margel, H., Eylon, B.-S., \& Scherz, Z. (2008). A longitudinal study of junior high school students' conceptions of the structure of materials. Journal of Research in Science Teaching, 45(1), 132-152.

McKagan, S.B., Perkins, K.K., \& Wieman, C.E. (2008). Why we should teach the Bohr model and how to teach it effectively. Physical Review Special Topics—Physics Education Research, 4(1), 010103.

McNemar, Q. (1947). Note on the sampling error of the difference between correlated proportions or percentages. Psychometrika, 12, 153-157.

Merritt, J., Krajcik, J., \& Shwartz, Y. (June, 2008). Development of a Learning Progression for the Particle Model of Matter. Paper presented at the International Conference for the Learning Sciences, Utrecht, Netherlands.

Minstrell, J. (1992). Facets of students knowledge and relevant instruction. In: R. Duit, F. Goldberg, \& H. Niedderer (Eds.), Proceedings of an International Workshop—Research in Physics Learning: Theoretical Issues and Empirical Studies (pp. 110-128). Kiel, Germany: The Institute for Science Education (IPN).

Mislevy, R.J., \& Riconscente, M. (2005). Evidence-centered assessment design: Layers, structures, and terminology. Menlo Park, CA: SRI International.

Mislevy, R.J., Steinberg, L.S., Almond, R.G., Haertel, G.D., \& Penuel, W.R. (2003). Leverage points for improving educational assessment. Menlo Park, CA: SRI International.

Mohan, L., Chen, J., \& Anderson, C.W. (in press). Developing a multi-year learning progression for carbon cycling in socio-ecological systems. Journal of Research in Science Teaching.

Nakhleh, M.B. (1992). Why some students don't learn chemistry. Journal of Chemical Education, 69(3), 191-196.

National Research Council. (1996). National Science Education Standards. Washington, D.C.: National Academy Press.

Niaz, M. (1998). From cathode rays to alpha particles to quantum of action: A rational reconstruction of structure of the atom and its implications for chemistry textbooks. Science Education, 82, 527-552.

Olsen, R.V. (2002). Introducing quantum mechanics in the upper secondary school: A study in Norway. International Journal of Science Education, 24(6), 565-574.

Pellegrino, J.W., Chudowsky, N., \& Glaser, R. (2001). Knowing what students know. Washington, DC: National Academy Press.

Pellegrino, J., Krajcik, J., Stevens, S.Y., Shin, N., Delgado, C., Geier, S., and members of the NCLT. (2008). Using Construct-Centered Design to align curriculum, instruction, and assessment development in emerging science. In: 
G. Kanselaar, V. Jonker, P.A. Kirschner, \& F. Prins (Eds.), Proceedings from ICLS '08: International perspectives in the learning sciences: Creating a learning world (Vol. 3, pp. 314-321). Utrecht, Netherlands: International Society of the Learning Sciences. Poster 2: Shin, N., Shawn, S.Y., Pellegrino, J., Krajcik, J.S., \& Geier, S. Construct-centered design.

Pellegrino, J., Krajcik, J., Shipley, E., Lopez Silva, B., Daly, S., Wischow, E., Moher, T., and members of the NCLT. (2008). Using Construct-Centered Design to align curriculum, instruction, and assessment development in emerging science. In: G. Kanselaar, V. Jonker, P.A. Kirschner, \& F. Prins (Eds.), Proceedings from ICLS '08: International perspectives in the learning sciences: Creating a learning world (Vol. 3, pp. 314-321). Utrecht, Netherlands: International Society of the Learning Sciences. Poster 6: Shipley, E., Lopez Silva, B., Daly, S., Wischow, E., Moher, T., \& Pellegrino, J.W. Using construct-centered design to revise instruction and assessment in a nanoscale self-assembly design activity: A case study.

Petri, J., \& Niedderer, H. (1998). A learning pathway in high-school level quantum atomic physics. International Journal of Science Education, 20(9), 1075-1088.

Piaget, J. (1983). Piaget's theory. In: P. Mussen (Ed.), Handbook of Child Psychology (Vol. 1, 4th ed.). New York: Wiley.

President's Council of Advisors on Science and Technology (PCAST). (2005). The National Nanotechnology Initiative at Five Years: Assessment and Recommendations of the National Nanotechnology Advisory Panel. Retrieved from http://www.nano-and-society.org/NELSI/entity/us_govt/NNI.html on December 20, 2008.

Renström, L., Andersson, B., \& Marton, F. (1990). Students' Conceptions of Matter. Journal of Educational Psychology, 82(3), 555-569.

Resnick, L.B. (1983). Mathematics and science learning: A new conception. Science, 220, 477-478.

Roseman, J.E., Linn, M.C., \& Koppal, M. (2008). Characterizing curriculum coherence. In: Y. Kali, M.C. Linn, \& J.E. Roseman (Eds.), Designing coherent science education. NY, NY: Teacher College Press.

Schmidt, W.H., Wang, H.C., \& McKnight, C.C. (2005). Curriculum coherence: An examination of US mathematics and science content standards from an international perspective. Journal of Curriculum Studies, 37(5), 525-559.

Shwartz, Y., Weizman, A., Fortus, D., Krajcik, J., \& Reiser, B. (2008). The IQWST experience: Using coherence as a design principle for a middle school science curriculum. The Elementary School Journal, 109(2), 199-219.

Shiland, T.W. (1997). Quantum mechanics and conceptual change in high school chemistry textbooks. Journal of Research in Science Teaching, 34(5), 535-545.

Simon, M.A. (1995). Reconstructing mathematics pedagogy from a constructivist perspective. Journal for Research in Mathematics Education, 26(2), 114-145.

Simon, M.A., \& Tzur, R. (2004). Explicating the role of mathematical tasks in conceptual learning: An elaboration of the hypothetical learning trajectory. Mathematical Thinking and Learning, 6(2), 91-104.

Sirhan, G. (2007). Learning difficulties in chemistry: An overview. Journal of Turkish Science Education, 4(2), 2-20.

Smith, C.L., Wiser, M., Anderson, C.W., \& Krajcik, J. (2006). Implications of research on children's learning for standards and assessment: A proposed learning progression for matter and the atomic molecular theory. Measurement: Interdisciplinary Research and Perspectives, 4, 1-98.

Stanitski, C.L., Eubanks, L.P., Middlecamp, C.H., \& Stratton, W.J. (2000). Chemistry in context: Applying chemistry to society (3rd ed.). Boston: McGraw Hill.

Stefani, C., \& Tsaparlis, G. (2009). Students' levels of explanations, models, and misconceptions in basic quantum chemistry: A phenomenographic study. Journal of Research in Science Teaching, 46(5), 520-536.

Stevens, S.Y., Shin, N., Delgado, C., Krajcik, J.S., \& Pellegrino, J. (April, 2007). Using Learning Progressions to Inform Curriculum, Instruction and Assessment Design. Paper presented at the National Association for Research in Science Teaching Conference, New Orleans, Louisiana.

Stevens, S.Y., Shin, N., Delgado, C., \& Krajcik, J.S. (April, 2007). Developing a Learning Progression for the Nature of Matter as it Relates to Nanoscience. Paper presented at American Educational Research Association, Chicago, IL.

Stevens, S.Y., Sutherland, L.M., \& Krajcik, J.S. (in press). The big ideas of nanoscale science and engineering: A guidebook for secondary teachers. Arlington, VA: NSTA Press.

Taber, K.S. (1998). An alternative conceptual framework from chemistry education. International Journal of Science Education, 20(5), 597-608.

Taber, K.S. (2000). Multiple frameworks?: Evidence of manifold conceptions in individual cognitive structure. International Journal of Science Education, 22(4), 399-417.

Taber, K.S. (2001a). Building the structural concepts of chemistry: Some considerations from educational research. Chemistry Education: Research and Practice in Europe, 2(2), 123-158.

Taber, K.S. (2001b). When the analogy breaks down: Modelling the atom on the solar system. Physics Education, 36(3), 222-226.

Taber, K.S. (2002). Conceptualizing quanta: Illuminating the ground state of student understanding of atomic orbitals. Chemistry Education: Research and Practice in Europe, 3(2), 145-158. 
Taber, K.S. (2004). Learning quanta: Barriers to stimulating transitions in student understanding of orbital ideas. Science Education, 89, 94-116.

Taber, K.S., \& Coll, R.K. (2002). Bonding. In: J.K. Gilbert, O.D. Jong, R. Justi, D.F. Treagust, \& J.H. Van Driel (Eds.), Chemical education: Towards research-based practice (pp. 213-234). Dordrecht, Netherlands: Kluwer Academic Publishers.

Tsaparlis, G. (1997). Atomic and molecular structure in chemical education: A critical analysis from various perspectives of science education. Journal of Chemical Education, 74(8), 922-925.

Tsaparlis, G., \& Papaphotis, G. (2002). Quantum-chemical concepts: Are they suitable for secondary students? Chemistry Education: Research and Practice in Europe, 3(2), 129-144.

Treagust, D.F., Harrison, A.G., \& Venville, G.J. (1996). Using an analogical teaching approach to engender conceptual change. International Journal of Science Education, 18(2), 213-229.

Uebersax, J.S., (2006). MH Program (Version 1.2) [Computer software]. Retrieved April 23, 2008, from http:// ourworld.compuserve.com/homepages/jsuebersax/mh.htm.

Unal, R., \& Zollman, D. (1999) Students' description of an atom: A phenomenographic analysis. Downloaded from http://perg.phys.ksu.edu/papers/vqm/AtomModels.pdf.

Wilson, M. (2005). Constructing measures: An item response modeling approach. Mahwah, New Jersey: Lawrence Erlbaum Associates.

\section{Appendix A}

Interview Protocol for the Nature of Matter

\section{Structure of Matter}

I have this sheet of metal. (Hand $4^{\prime \prime} \times 6^{\prime \prime}$ sheet of aluminum to them.) Imagine that we have an instrument that lets us "zoom in" and see what it's made of-What do you think the surface would look like? Will you draw it for me? Explain to me what I'm looking at. (probe as necessary)

- If they don't get down to the atomic/molecular scale, then continue to find out their perception of fundamental structure. (If student doesn't understand, ask him/her to draw what a "speck" of metal looks like from very close, "blow it up big on this paper.")

If they draw particles:

- What are those dots (or whatever) you have drawn? What do they represent?

- How big are they?

- About how many do you think there are in the whole sheet?

- Are they 2D or 3D (like a penny or a marble)?

If appropriate from the picture:

Those particles are in a very regular pattern.

- What makes them arrange like that?

- Do they have to be in that arrangement?

- What makes them stay that way?

- Why don't they fall apart?

- What's in the space between the particles?

How many particles do you think are stacked up to make the metal this thick $(\sim 0.5 \mathrm{~mm})$ ? The edge looks like it would be lumpy the way you've drawn it. (point to edge the last row of circles) Why does it feel so smooth?

If somehow different than bulk/center particles-ask them to draw the edge. 
Now let's heat the metal and melt it.

- What is happening when it melts?

- Is anything happening to the particles? (size, shape, number)

Would you draw a picture of what it looks like now? Explain what I'm looking at. (probe as necessary): You have drawn some difference between the pictures of the liquid and solid form of this substance.

- Is there anything different about the particles in this liquid versus the solid up here?

It looks like you drew more space between your particles here than in the solid.

- Why is that?

- What's in that space?

OR if continuous

You haven't drawn any particles in the liquid.

- What happened to them?

\section{Change of Properties With Scale; Forces and Interactions}

Now we're going to talk about a different substance. Here are 3 forms of sugar-a big crystal or rock candy, granulated sugar and powdered sugar.

- Would you still consider these to be the same substance?

If no, why not? don't)

(note-for 7th grade especially, make sure that they know what a substance is. Define it for them if they

- Which properties do you think are the same? Different?

- Do you think the sugars act the same way no matter what size it is?

Here is a little experiment using our sugar samples.

Pour the granulated sugar and powdered sugar off of the black contact paper. Do not tap on table.

- Do you notice any differences in the behavior of the two samples?

- What differences do you see?

- What do you think causes those differences?

Part of the card is covered with a single layer of powdered sugar, and part has some clumps of sugar.

- What's keeping it from falling down?

- What's keeping the clumps together and stuck to the card?

- How come most of the powdered sugar did fall down?

- Why aren't there any clumps on the regular sugar card?

OK, now powdered sugar is made up of pretty small pieces but we can keep crushing it up even more. How long can I keep crushing it up (Renström, Andersson, \& Marton, 1990)? What is the smallest piece of sugar there can be?

If get to molecules:

- Is there anything different about properties of sugar molecules than the sugar we see here?

- What makes the molecules come together and stay together to make the substance that we can see and use? 
- Is this going to be the same for any substance? Even liquids?

- How would water molecules interact? Can you draw 3 of them for me?

If get "disappeared" or "it's gone," etc., probe further.

Do you mean completely gone, or too small to see?

- If the latter, then invoke the special tool to see and another to cut tiny things.

Here is another substance that looks a lot like sugar. However, it came from a chemistry lab. How can we tell them apart?

- Probe for properties, tests learned in science class, etc.

\section{Atomic Model}

Do you know what an atom is?

- Why are atoms important?

Think about what an atom looks like.

- Would you please draw a picture of an atom for me?

Describe what I'm looking at.

If they get to protons, neutrons and electrons:

Tell me about $\mathrm{p}, \mathrm{n}$, and $\mathrm{e}$.

- How do they compare?

- Is the number of $\mathrm{p}, \mathrm{n}, \mathrm{e}$ important?

Ask about electron motion as appropriate for the drawing:

For example, if they draw orbitals, but don't say anything about electron movement-That looks a lot like a solar system. Do the electrons orbit around like planets?

- Is your drawing to scale?

\section{Inter-Atomic Interactions}

Atoms combine to make up all of the substances around us. Two examples are chlorine and sodium chloride. (Give them the Periodic Table and a paper with formulas written on them.) Can you explain why the atoms combine in these ways?

- What is different about how these two substances are formed?

- What would $5 \mathrm{Cl}_{2}$ look like? $5 \mathrm{NaCl}$ ?

\section{Appendix B}

Figure B1B represents the data for step between B and C from the Guttman scale (Figure B1A). Eighteen students understand B and $\mathrm{C}$, one student discussed $\mathrm{C}$, but not B, eight students discussed B but not C and eight students discussed neither. The McNemar test gives a $p$-value of 0.0391 for the step from B to C, suggesting that this is an ordered connection. In contrast, Figure B1C representing the step between D to $\mathrm{E}$ results in a $p$-value of 0.453 , which indicates that the step is not statistically significant. Further testing is then required to ascertain whether $\mathrm{E}$ should be combined with $\mathrm{D}$ or $\mathrm{F}$, or is part of a divergent branch from $\mathrm{C}$. 
A

\begin{tabular}{|c|c|c|c|c|c|c|c|c|c|}
\hline Student & A & \begin{tabular}{l|l}
$A$ & $B$ \\
\end{tabular} & $\begin{array}{ll}3 & C \\
\end{array}$ & \begin{tabular}{|l|}
$D$ \\
\end{tabular} & \begin{tabular}{l|l}
$E$ & $F$ \\
\end{tabular} & $\mathrm{~F} G$ & $\mathrm{H}$ & \begin{tabular}{|l|l|}
1 & 3 \\
\end{tabular} & \begin{tabular}{|l|l|l|}
$\mathrm{K}$ & $\mathrm{L}$ & $\mathrm{M}$ \\
\end{tabular} \\
\hline Concept F & 1 & \begin{tabular}{l|l}
1 & 1 \\
\end{tabular} & \begin{tabular}{|l|l|}
1 & 1 \\
\end{tabular} & \begin{tabular}{|l|}
1 \\
\end{tabular} & \begin{tabular}{l|l}
1 & 0 \\
\end{tabular} & \begin{tabular}{|l|l|}
0 & 0 \\
\end{tabular} & 0 & \begin{tabular}{|l|l|}
0 & 0 \\
\end{tabular} & \\
\hline Concept E & 1 & \begin{tabular}{l|l}
1 & 1 \\
\end{tabular} & \begin{tabular}{l|l}
1 & 1 \\
\end{tabular} & 1 & 1 & 1 & 1 & \begin{tabular}{l|l}
0 & 0 \\
\end{tabular} & 0 \\
\hline Concept D & & \begin{tabular}{l|l}
1 & 1 \\
\end{tabular} & \begin{tabular}{l|l}
1 & 1 \\
\end{tabular} & $1 \mid$ & \begin{tabular}{l|l}
1 & 1 \\
\end{tabular} & 1 & 1 & 1 & 1 \\
\hline Concept C & & \begin{tabular}{l|l}
1 & 1 \\
\end{tabular} & \begin{tabular}{l|l}
1 & 1 \\
\end{tabular} & \begin{tabular}{|l|}
1 \\
\end{tabular} & \begin{tabular}{l|l}
1 & 1 \\
\end{tabular} & \begin{tabular}{|l|l|}
1 & 1 \\
\end{tabular} & 1 & \begin{tabular}{|l|l|}
1 & 1 \\
\end{tabular} & \begin{tabular}{|l|l|}
1 & 1 \\
\end{tabular} \\
\hline Concept B & & \begin{tabular}{l|l}
1 & 1 \\
\end{tabular} & \begin{tabular}{l|l|}
1 & 1 \\
\end{tabular} & 1 & \begin{tabular}{l|l}
1 & 1 \\
\end{tabular} & \begin{tabular}{l|l|}
1 & 1 \\
\end{tabular} & 1 & \begin{tabular}{|l|l|}
1 & 1 \\
\end{tabular} & \begin{tabular}{|l|l|l}
1 & 1 & 1 \\
\end{tabular} \\
\hline Concept A & 1 & \begin{tabular}{l|l}
1 & 1 \\
\end{tabular} & \begin{tabular}{|l|l|}
1 & 1 \\
\end{tabular} & \begin{tabular}{|l|}
1 \\
\end{tabular} & \begin{tabular}{l|l}
1 & 1 \\
\end{tabular} & \begin{tabular}{l|l|l|}
1 & 1 \\
\end{tabular} & 1 & \begin{tabular}{|l|l|}
1 & 1 \\
\end{tabular} & \begin{tabular}{|l|l|l|}
1 & 1 & 1 \\
\end{tabular} \\
\hline 3 & $C(1)$ & C & $c(0)$ & & & ? & & $E(1)$ & $E(0)$ \\
\hline $\mathbf{B ( 1 )}$ & 18 & & 8 & & & $D(1$ & 1) & 8 & 5 \\
\hline $\mathbf{B}(0)$ & 1 & & 8 & & & $\mathrm{D}(\mathrm{C}$ & & 2 & 20 \\
\hline
\end{tabular}

Figure B1. Examples of (A) Guttman scaling and (B) $2 \times 2$ tables with McNemar analysis. 